\title{
The influence of seasonal climate on the morphology of the mouth-bar in the Yangtze Estuary, China
}

\author{
Min Zhang ${ }^{\mathrm{a}, \mathrm{b}}$, lan Townend ${ }^{c}$, Huayang Cai ${ }^{\mathrm{d}}$, Jiawei He ${ }^{\mathrm{d}}$, Xuefei Mei ${ }^{\mathrm{b}, \mathrm{e}_{*}}$, \\ a Shanghai Normal University, Department of Geography, Shanghai, China \\ b East China Normal University, State Key Laboratory of Estuarine and Coastal Research, Shanghai, \\ China \\ c University of Southampton, Ocean and Earth Sciences, Southampton, United Kingdom \\ d Sun Yat-sen University, School of Marine Sciences, Guangzhou, China \\ e Delft University of Technology, Faculty of Technology, Policy and Management, Delft, The \\ Netherlands
}

\section{ABSTRACT}

The geomorphology of the Yangtze Estuary in the Changjiang River Delta in Eastern China has been the subject of extensive research. This study extends previous work to examine the influence of wind-waves on the mouth-bar, where about half of the river-borne material settles to the bed. The site is located just outside of Changjiang River mouth, which is meso-tidal and subject to seasonally varying river flows and wind-wave conditions. Modeling was performed with a coupled wave-current hydrodynamic model using TELEMAC and TOMAWAC and validated against observed data. Bottom Shear Stress (BSS) from river, tide and waves based on the numerical model output was used to infer the respective contribution to the evolution of the subaqueous delta. Our examination did not however extend to modeling the sediment transport or the morphological bed changes. The results suggest that (i) the dominance of river discharge is limited to an area inside the mouth, while outside, the mouth-bar is tide-wave dominant; (ii) considering just the tide, the currents on the shallow shoals are flood dominant and deep channels are ebb dominant, which induces continued accretion over the shallows and erodes the deeper parts of the mouth-bar until the tidal currents become too weak to transport sediment; (iii) whereas waves are very efficient at reshaping the shallow shoals, with the effect being subtly dependent on the depth distribution over the mouth-bar; (iv) the stability of shallow shoal morphology is highly dependent on the presence of seasonal wind-waves and characterized as "summer storing and winter erosion", while deep channels perform like corridors of water and sediment, exporting sediment all year round. The nature of the mouth-bar response has important implications for coastal management, such as the ongoing deep water channel maintenance, reclamations and coastal defense measures.

Keywords: Bottom shear stress; wave-current interaction; mouth bar; estuary geomorphology; seasonal; Yangtze Estuary

\section{Introduction}

Estuary geomorphology is strongly controlled by hydrodynamics from both fluvial and marine processes (Dai et al., 2014), i.e. the driving forces of river, tide and waves. The Yangtze Estuary, located at the landward margin of the East China Sea shelf (Figure 1a), connects the river to the open sea and has evolved under these complex interactions. The previous main outlet of the North Branch had shifted to the South Branch, following the divergence of the mainstream in the $18^{\text {th }}$ century (Chen et al., 1985). Since then the South Branch has narrowed with the growth of Chongming Island, Changxing Island and Hengsha Island (Figure 1b), and the impact of waves on the inner reach morphology has weakened due to the sheltering of these islands (Chen et al., 
1985) . However, the location of the outlet was rapidly extended seaward due to a series of reclamations (at Chongming and Nanhui east shoal) and siltation (at Hengsha east shoal) due to a series of projects the began in the 1950s (Chen et al., 1985; Dai et al., 2016; Du et al., 2016) . As a result, the estuary mouth and mouth-bar are now subject to direct wave action without the protection of the islands the previous estuary mouth had.

The regional East Asia Monsoon climate where Yangtze Estuary is located, has two well defined seasons. During the summer months (April-September), runoff is large and dominant and the waves have a predominant north-west direction but are relatively small. In contrast, during the winter months (October-March) the runoff is small and the waves are much bigger and predominantly from a south-east direction (Zhu et al., 2017). As a result, wave-current interaction (WCI) will vary with the seasonal changes in runoff and waves. When combined with the influence of tide, it can be expected that the hydrodynamics of river-tide-wave interactions at the mouth-bar will be complex. The seasonal variations of hydrodynamics will subsequently control and affect the seasonal sediment transport and morphological evolution. Since ports are often located in naturally sheltered areas inside of mouth-bar, the morphological evolution in this area may affect port operations, limiting the time for vessels to access, or depart from, a port. Ports are usually economically significant to the region, and a proper understanding of the port entrance can help ensure sustainable access. Hence, knowledge of potential mouth-bar sediment transport patterns can be important for port management.

Some insight into how the hydrodynamic forcing drives morphological change is made possible by analyzing bed shear stress (BSS) to identify the predominant driving forcing that leads to sediment mobility. BSS suspends sediment (Dalyander et al., 2013b), dissipates energy (van der Wegen et al., 2008) and contributes to short term micro-topography change as well as the long term morphology evolution (Lu et al., 2015). We consider the resultant hydrodynamic forcing using the total BSS, as the combined effect of currents due to tide, river and waves. In recent decades, there has been an increasing interest in the use of BSS to examine morphological change in estuarine environments, through both numerical modeling (Bolla Pittaluga et al., 2015; Guo et al., 2014; Lanzoni and Seminara, 2002)and laboratory experiments (Vlaswinkel and Cantelli, 2011). However, such studies tend to highlight the dominance of tidal BSS in controlling the estuary morphology because their focus is within the estuary. In more open coast environments, wave BSS can be far more effective than tides at shaping shallow shoals (Zhu et al., 2017; Hunt et al., 2015). Furthermore, neglecting the non-linear effects of wave and tide will significantly underestimate the total BSS (Zhu et al., 2017; Dalyander et al., 2013a; Malarkey and Davies, 2012). Recent work by Zhu et al. (Zhu et al., 2017; Zhu et al., 2016; Zhu et al., 2014) estimated intra-tidal sedimentary processes at Nanhui and Chongming east shoal with measured total BSS, however little quantification and description of BSS over longer time periods and at a regional scale has been carried out, mostly because field measurement can only be performed at a few select locations over a relatively short period (Dalyander et al., 2013b). Regional scale study is made possible by using numerical modeling technique that examine seasonal scenarios of wind and waves and how these interact with the tidal process. With this approach, it is possible to examine the potential sediment mobility at both the tidal scale and seasonal scale and this is the focus of the work presented here.

The development and stability of the Yangtze Estuary has been the subject of research by many authors and on various short to long timescales. Guo et al. (2014) evaluated the significance of 
the tidal asymmetry (tidal scale) to the morphological equilibrium of the Yangtze Estuary. By combining field measurements with model simulations, Zhu et al. (2017) were able to quantify short-term tidal flat changes at Yangtze Estuary (spring-neap scale). They observed erosion during neap to-mean tides and recovery during subsequent spring tides. Based on multi-year monitoring records in the Yangtze Estuary (inter-annual scale), Wei et al. (2015) were able to investigate the temporal-spatial changes of tidal flats. Other long-term equilibrium characteristics of the Yangtze Estuary at the regional scale have been investigated extensively from decadal to millennial timescales (Chen et al., 1982; Dai et al., 2015; Wang et al., 2013; Yang et al., 2001). Despite these short-term and long-term studies, little is known regarding the medium timescales of seasonal development over the mouth-bar area. Observations in the last few decades do identify obvious seasonal variation in water and sediment discharges, wind-waves and the resultant hydrodynamics (Xu and Milliman, 2009; Kuang et al., 2017; Zhang et al., 2016; Zhou et al., 2015). However no detailed research has been conducted to relate this to sedimentation process over the mouth-bar area. Seasonal sedimentation processes have been well studied both inside the mouth (Guo et al., 2014; Lanzoni and Seminara, 2002) and in open continental shelf environments (Guo et al., 2003; Liu et al., 2010; Wang et al., 2007). Even so, the seasonal influences of river, tides, and waves on sedimentation are far from being well understood. Such seasonal bed level variations have been demonstrated in other estuaries in temperate latitudes, where calmer, warm summers and windy, cold winters tend to result in a "winter" and "summer" profile (O Brien et al., 2000), such as in the Bristol Channel (Kirby and Kirby, 2008), the Deben (Frostick and McCave, 1979) and the Tamar (Bale et al., 1985) in the UK and Chesapeake Bay in USA (Kraeuter and Wetzel, 1986).

In this study, we extend our previous research of river-tide interactions (Zhang et al., 2016a; Zhang et al., 2016b) by including wind-waves, to investigate the seasonal morphological characteristics of the outer delta. The main objective of this paper is to investigate the mouth-bar responses to tide, river and wind-wave parameters related to seasonal changes of different wind forcing and runoff conditions, to gain a better understanding of seasonal mouth-bar evolution. In addition, we explore the stability of mouth-bar evolution over different timescales from the perspective of potential sediment mobility. The focus is on analyzing the combined effects over the shallow shoals and deep channels in terms of BSS estimation and energy dissipation. Use is made of a coupled wave-current hydrodynamic model to examine particular river, tide and wave processes in isolation by neglecting other forces. The results from this reductionist modeling approach have allowed us to infer how the relationship between hydrodynamics and BSS, influences the resultant mouth-bar stability over typical summer and winter seasons. The results are interpreted making use of the available field observations.

\section{Study area}



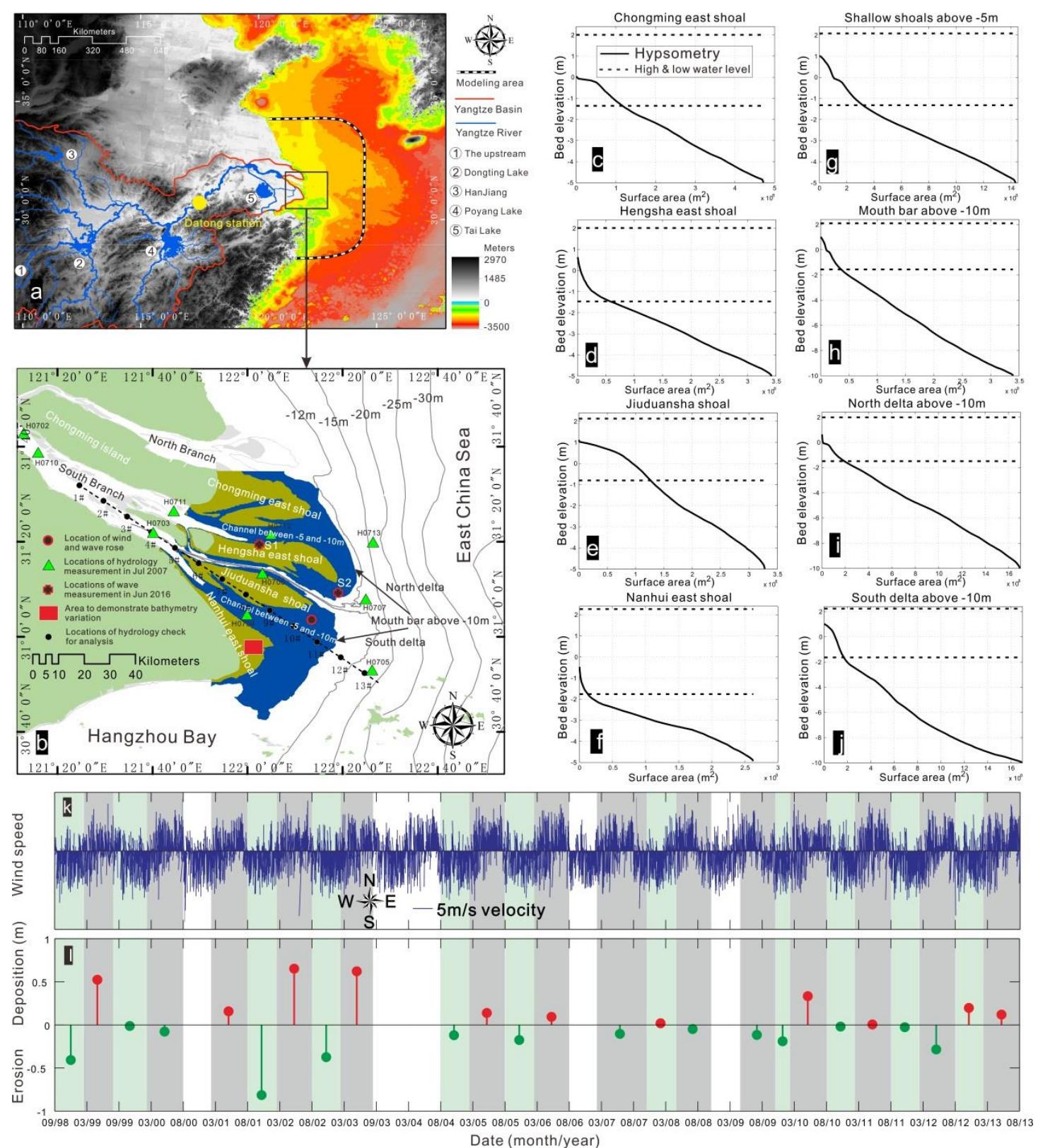
Date (month/year)

Figure 1. (a) Location map and bathymetry for the east coast of China; (b) mouth of the Yangtze showing the regional enlarged map of mouth-bar area (blue and yellow colors), the locations of field hydrology measurement (green triangle) in July 2007, June 2016, location of wind and wave rose, and seasonal bathymetry validation (red square) from September 1998 to August 2013; (c-j) bed hypsometry for the areas denoted in (b); (k) wind vector off Nanhui coast; (I) averaged erosion and deposition thickness over the red square frame denoted in (b) derived from subtraction of consecutive bathymetry maps in the time series, positive (red) is deposition and negative (green) is erosion. The colored background indicates the duration of changes that happened, in which gray is around the summer season and green is around the winter season (for the data available, the duration is not strictly following summer-winter division).

The Yangtze Estuary, located on the east coast of China (Figure 1a), is the main outlet of the Changjiang river basin, flowing in to the East China Sea. Bifurcations are typical landforms of the estuary. The three orders of bifurcation are positioned en echelon to the southeast direction. The 
$1^{\text {st }}$ order bifurcation forms the North Branch and South Branch either side of Chongming Island, the $2^{\text {nd }}$ order of bifurcation divides the South Branch into the North Channel and the South Channel past Changxing Island, and the $3^{\text {rd }}$ bifurcation subdivides the South Channel into North Passage and South Passage around Jiuduansha Shoal (Figure 1b). East of Chongming Island, Hengsha Island and Nanhui is the mouth-bar area, where tongue-shaped shallow shoals are divided by deep channels (Figure 1b). More than $99 \%$ of the sediment delivered to the estuary is consists of silt and clay, in the form of suspended sediment (Luan et al., 2017). The mean suspended sediment concentration (SSC) of the whole estuary is $0.46 \mathrm{~g} / \mathrm{l}$ (1951-2005), and the median grain size $\left(D_{50}\right)$ is $9 \mu \mathrm{m}$ (1987-2005) (Liu et al., 2010), while at the mouth-bar the SSC is higher, generally 1-3 g/l (Dai et al., 2013; Yang et al., 2001) and clayey silt is the dominant sediment type (Liu et al., 2010). Bed load of fine sand is often found in deep channels of the South Branch, while the grain size over the mouth-bar area is more variable; the deep channels are finer $\left(D_{50}=8\right.$ to $\left.180 \mu \mathrm{m}\right)$ than the shoals ( $D_{50}=62$ to $250 \mu \mathrm{m}$ ) (Chen et al., 1985). The fluvial runoff in the Yangtze catchment is large and seasonally variable (Xu and Milliman, 2009). The multi-annual (1950-2012) mean runoff recorded at the Datong hydrographic station (Figure 1a), which is the most downstream large-scale hydrological station along the main stream of the Yangtze river, is about $28310 \mathrm{~m}^{3} / \mathrm{s}$, of which $\sim 99 \%$ of the discharged water flows through the South Branch (Zhang et al., 2012). The monthly mean discharge varies significantly from an average of $35000 \mathrm{~m}^{3} / \mathrm{s}$ during the wet season (April-September) to an average of $15000 \mathrm{~m}^{3} / \mathrm{s}$ during the dry season (October-March). The significant changes in seasonal discharge is reflected in the variation of the Canter-Cremers number (the ratio of the river discharge to the flood tide discharge during a mean spring tide), which varies from about 0.1 in the dry season to about 0.5 in the wet season at the mouth of the South Branch. As a result, the Yangtze Estuary is a completely river dominated system in the summer season, but it changes to be a marine 


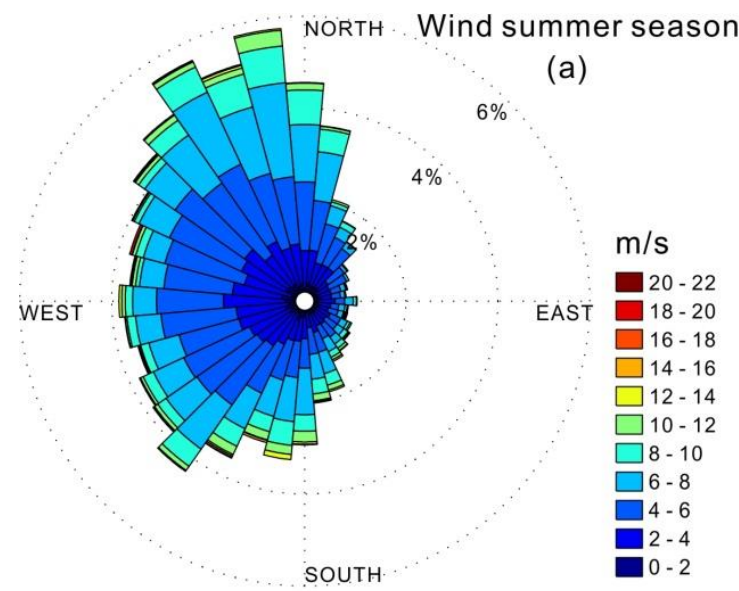

NORTH Wave summer season

(c)

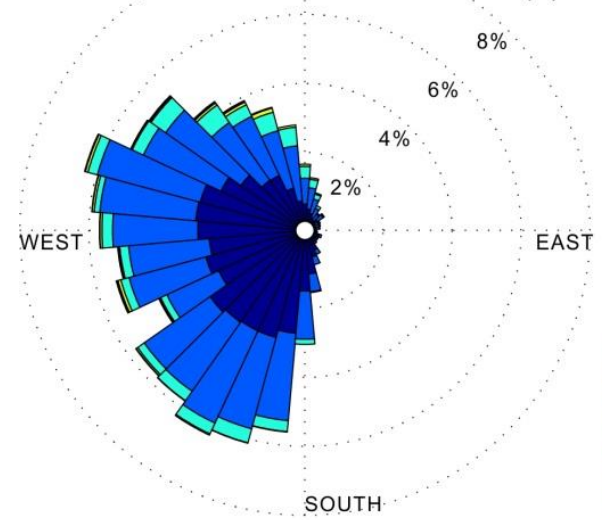

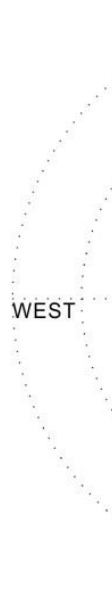

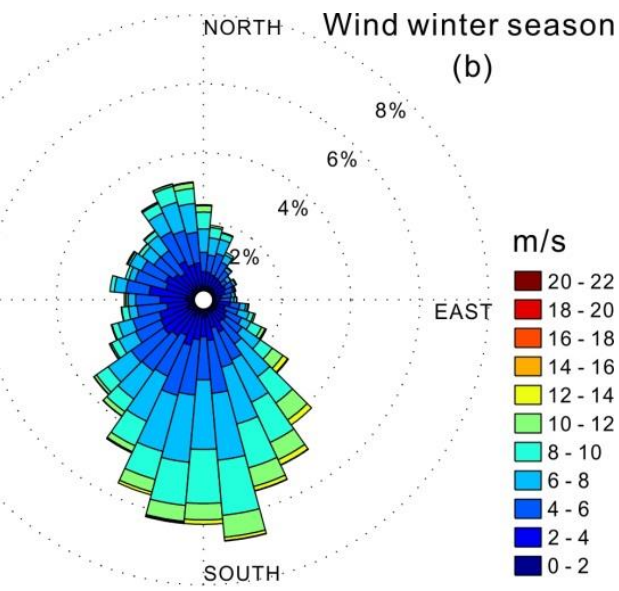

Wave winter season

(d)

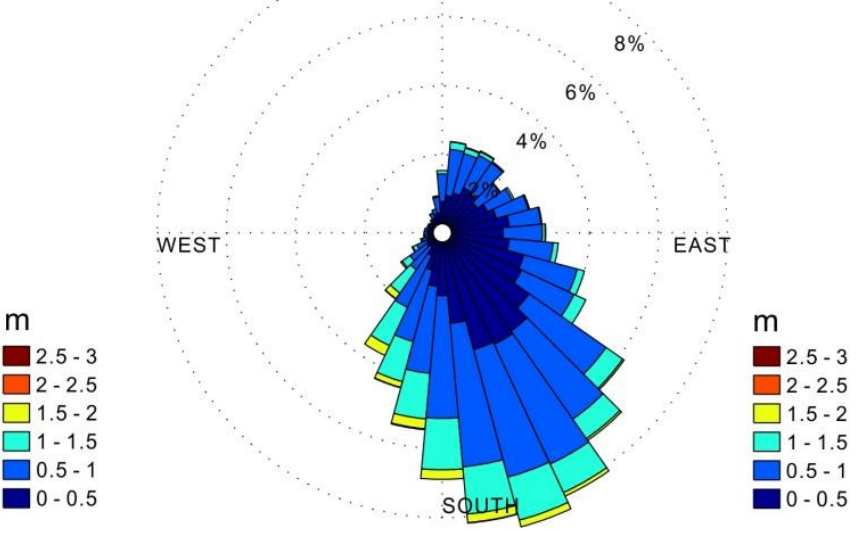

Figure 2. Wind and wave roses measured on the east side of Yangtze Estuary, as shown in Figure 1b. Sectors indicate the wave direction or the direction the wind vector is directed towards. The color scales for the wind and wave roses are wind speed $(\mathrm{m} / \mathrm{s})$ and significant wave height $(\mathrm{m})$, respectively.

Seasonal variations also lead to notable changes in the winds and waves in the area. These variations are illustrated in Figure 2, which shows directional wind and wave roses for the summer (April-September) and winter (October-March) seasons, based on 11 years (2002-2012) of archived data provided by QuikSCAT (http://www.remss.com/missions/qscat) and ECMWF (http://www.ecmwf.int/). The winds are relatively dispersed but generally blow from east in summer season (Figure 2a). A similar pattern is identified for the wave propagation (Figure $2 \mathrm{c}$ ). In the winter season, the winds change to downward dominant (Figure $2 b$ ) and the wave direction turns to match the wind dominance (Figure $2 \mathrm{~d}$ ). The consistency of waves and winds indicates the predominance of waves generated by local winds over the estuary and adjacent coastal region. According to historical records at Sheshan wave station (1998-2009 year), located east of Hengsha Island, the dominant wave direction changes from westerly to southeasterly with an occurrence of $67 \%$. The monthly mean wave height ranges from $0.38 \mathrm{~m}$ (June) to $0.82 \mathrm{~m}$ (December) with an average wave period of 3.95-5.02s. Generally, the wave periods produced by local winds are less than $6.5 \mathrm{~s}$, however some records at Sheshan wave station reach above $10 \mathrm{~s}$, indicating swell propagating from open seas.

The local tides are of irregular semi-diurnal type, with mean spring tidal ranges at the stations 
Baimaosha and Niupijiao located in and out of the mouth are $3.1 \mathrm{~m}$ and $4.2 \mathrm{~m}$, respectively (Yang et al., 2001). The estuary experiences strong tidal currents with an estimated tidal prism of $2.5 \times 10^{9} \mathrm{~m}^{3}$ during spring tide and $1 \times 10^{9} \mathrm{~m}^{3}$ during neap tide. Tidal asymmetry is reflected on the flood and ebb processes, where the average flow velocity of flood tides is $\sim 1 \mathrm{~m} / \mathrm{s}$, which is lower than the ebb velocity of $\sim 1.2 \mathrm{~m} / \mathrm{s}$. The ebb duration is longer $(\sim 7.4 \mathrm{~h})$ than the flood duration $(\sim 5 \mathrm{~h})$ in the inner river mouth, but flows become progressively similar in duration when approaching the mouth-bar area (Li et al., 2011).

\section{Methodology}

A numerical modeling method with simplified boundary conditions is adopted, which, despite being idealized, aims to represent the typical characteristics of the dominant hydrodynamics. The advantages of using idealized configurations is that the simplified model can be systematically manipulated to test scenarios of representative conditions, while the reduced complexity enables greater insight into the respective influences. A coupled depth-averaged wave-current model is used that is able to represent the processes of interest over the full extent of the tidal river and an area of the East China Sea that is sufficiently large to ensure that the tidal boundaries are remote from the area of interest. In this section, details of the data sources for the model, the model set-up and the model validation are outlined.

\subsection{Wave and flow models}

The hydrodynamics of the free surface and flow is computed with TELEMAC-2D module of the TELEMAC-Mascaret modeling suite. The TELEMAC-2D module is a finite element model, which solves the depth-averaged Navier Stokes Equations in shallow water with several options for diffusion terms and source terms (Hashemi et al., 2015):

$$
\begin{gathered}
\frac{\partial \mathrm{h}}{\partial \mathrm{t}}+\mathrm{U} \cdot \nabla(\mathrm{h})+\mathrm{h} \nabla \cdot \mathrm{U}=S_{h} \\
\frac{\partial \mathrm{U}}{\partial \mathrm{t}}+\mathrm{U} \cdot \nabla(\mathrm{U})=-\mathrm{g} \nabla\left(z_{w s}\right)+\frac{1}{\mathrm{~h}} \nabla \cdot\left(\mathrm{h} v_{t} \nabla \mathrm{U}\right)+S_{u}
\end{gathered}
$$

where $S_{h}$ is source terms of the mass continuity equation, $v_{t}$ is the momentum diffusion terms (depth-averaged Elder model or constant eddy viscosity model), $S_{u}$ represent other forces (friction, wind, Coriolis force, wave forces, etc.). All other symbols are listed in the Notation.

TOMAWAC, on the other hand, is the wave module of the TELEMAC-Mascaret modeling suite, which solves the balance equation of the wave action density directional spectrum. To serve this purpose, TOMAWAC accounts for the effect of deep and shallow water physics, i.e. waves generated by wind, wave propagation and refraction, non-linear wave-wave quadruplet and triad interactions, and dissipation (i.e. white-capping, bottom friction and depth-induced wave breaking) (TOMAWAC operating manual, www.telemacsystem.com.). TOMAWAC can be applied to the same node of the spatial computational grid as used in the TELEMAC-2D flow model. By using a direct coupling, the free surface elevations and currents are provided to TOMAWAC by TELEMAC, while TOMAWAC generates waves with reference to those current and water depth, and the returning information are the updated values of the wave driving forces acting on the current to TELEMAC (TOMAWAC operating manual, www.telemacsystem.com.). There are different possible approaches to define the transfer of the current velocity field (Fan et al., 2009). The wave-averaged effects on the tide calculated by TOMAWAC can be interpreted as a radiation 
stress (Jia et al., 2015):

$$
S_{i j}=\rho g \int_{0}^{2 \pi} \int_{0}^{+\infty}\left[\frac{C_{g}}{C} \frac{k_{i} k_{j}}{k^{2}}+\left(\frac{C_{g}}{C}-\frac{1}{2}\right) \delta_{i j}\right] \times F(f, \theta) d f d \theta
$$

while, the radiation stress forcing term $\left(S_{u}\right)$ that is returned and solved by TELEMAC-2D in equation (2) is formulated as (Jia et al., 2015):

$$
S_{u}=-\frac{1}{h \rho}\left(\begin{array}{l}
\frac{\partial S_{x x}}{\partial x}+\frac{\partial S_{x y}}{\partial y} \\
\frac{\partial S_{y x}}{\partial x}+\frac{\partial S_{y y}}{\partial y}
\end{array}\right)
$$

where $S_{x x}, S_{y y}, S_{x y}$ and $S_{y x}$ are four components of the radiation stress tensor of equation (3). The meanings of other symbols are listed in the Notation.

\subsection{Data sources used to set-up model}

The observed data used in the present work came from four sources, including field measured data, historically archived data, satellite retrievals and published models. The bottom boundary of the Yangtze Estuary was defined using navigation charts collected for the years 2007 and 2008. Each chart consists of several sub-charts with different scales, i.e. the upstream river channel (1:25 000), the North Branch and South Branch (1:50 000), the North Channel and South Channel (1:25 000), the North Passage and South Passage (1:25 000), and the mouth offshore (1:100 000). The adjacent Hangzhou bay and parts of continental shelf that are not covered by navigation charts were compiled from the GEBCO global bathymetric database (http://www.gebco.net). A mosaic of the bathymetry of the study area was compiled by the assimilation of heterogeneous data types having corrected to mean sea level of Huanghai1985 datum in ArcGIS. Daily river discharges measured at the Datong gauge station (Figure 1a) were used to force the Yangtze riverward open boundary, while at the seaward open boundary harmonic constituents of depth averaged velocity and surface elevations from the TPX07.2 global ocean tidal model (http://volkov.oce.orst.edu/tides) were imposed.

To properly simulate waves in the semi-enclosed Yangtze Estuary and open seas, high-resolution meteorological forcing is needed to define the atmospheric boundary within the model (Carr et al., 2016). In this study, the atmospheric forcing employed (i.e., wind field at $10 \mathrm{~m}$ above sea level and atmospheric pressure) was provided by the Quick Scatterometer, a series of SeaWinds instruments placed in orbit (http://www.remss.com/missions). These satellite-borne scatterometers were launched in June 1999 and are still operational (superseded by ASCAT after November 2009), and provide standard 10-m surface vector wind over the global oceans at 25 $\mathrm{km}$ gridded intervals in polar orbits with swaths between $500 \mathrm{~km}$ and 1,100 km wide. Satellite winds are only available at 6 hour intervals but have a high spatial resolution, allowing them to be interpolated onto a $12.5 \mathrm{~km}$ horizontal grid. The resultant data are therefore a suitable source to define the atmospheric boundary over a large area. This is important in a region like the Yangtze Estuary, where specific local effects of orographic constraints and thermal contrast between land and sea, produces rapidly varying and spatially distributed sea surface wind fields seasonally (Li et al., 2015). A validation of wind field from QuikSCAT using buoy data in the Indian Ocean (Satheesan et al., 2007), found that the mean value and RMS deviation of differences to be about 0.37 and $1.57 \mathrm{~m} / \mathrm{s}$ for wind speed and $5.8^{\circ}$ and $44.1^{\circ}$ for wind direction, respectively. Similar validation by Pensieri et al. (2010) and Plagge et al. (2009) also lend credence to the QuikSCAT wind product, both in the open oceans and the coastal regions. They have also shown 
how the wind field resolution is crucial for the accurate reproduction of the dominant and transient wind-waves in the semi-enclosed areas; suggesting that wind fields with a horizontal grid size smaller than $20 \mathrm{~km}$ can significantly improve the accuracy for wave numerical modeling (Benetazzo et al., 2013).

271 The resulting model for the Yangtze Estuary has been calibrated and verified using observed data. A total of 10 observational sites (i.e. H0702, H0703, H0704, H0705, HO706, H0707, H0710, H0711, H0712, and H0713, Figure 1b) from the inner to outer estuary were used to characterise the nature of tides at spring and neap. Flood and ebb portions of the tide were measured at the above 10 sites from 22-24 July and 29-31 July, 2007. Observations were used with upward-looking Acoustic Doppler Current Profiler (ADCP) (SonTek-500) and direct-read current meters (SLC9-2) to measure the flow direction and velocity (Zhang et al., 2016b). Another two synchronously observations from 7 to 10 June, 2016 were carried out around east Hengsha shoal (Lat $=31^{\circ} 9^{\prime} 18^{\prime \prime}$, Lon $=122^{\circ} 18^{\prime} 38^{\prime \prime}$; Lat $=31^{\circ} 19^{\prime} 50^{\prime \prime}$, Lon $=122^{\circ} 1^{\prime} 3^{\prime \prime}$, see Figure $\left.1 \mathrm{~b}\right)$, where local water depth is approximately $6 \mathrm{~m}$ and $9 \mathrm{~m}$. Observations were used with a depth-current wave sensor with a wave burst sample rate of $4 \mathrm{~Hz}$, wave burst sampling period of $10 \mathrm{~min}$, together with Nortek AS AWAC current profiler and wave directional system to measure wave and tidal amplitude damping across the mouth-bar area (Yu et al., 2016). The manufacturers stated accuracy for current is $1 \%$ of the measured value, and the accuracy of wave elevation and direction is $1 \mathrm{~cm}$ and $2^{\circ}$, respectively.

Because of the sparsity of field measured wave data, validation also made use of observations from ERA-Interim's operational archive. ERA-Interim is the latest global reanalysis produced by the European Centre for Medium-Range Weather Forecasts (ECMWF, http://www.ecmwf.int/). Gridded data of ERA-Interim, describing global ocean wave in spatial and temporal resolutions of $25 \mathrm{~km}$ and $6 \mathrm{~h}$, covers the period from 1 January 1979 to an almost near-real time. The advantage of ERA-Interim reanalysis is that it provides a multivariate, spatially complete, and homogeneous record, unaffected by changes in observing system, or the presence of time-varying biases in models (Bechtold et al., 2008). As a result, numerous researchers have used ERA-Interim products as a surrogate for observations for monitoring and assessment of global climate change, although the adequacy of these records is still open to debate (Berrisford et al., 2011). However, Dee et al. (2011) argued "substantial progress has been made over the years in producing global estimates of the basic dynamical fields that are consistent with observations given their estimated uncertainties". Therefore, it is reasonable to consider ERA-Interim wave reanalysis data, in tandem with observed wave data, for model validation. 


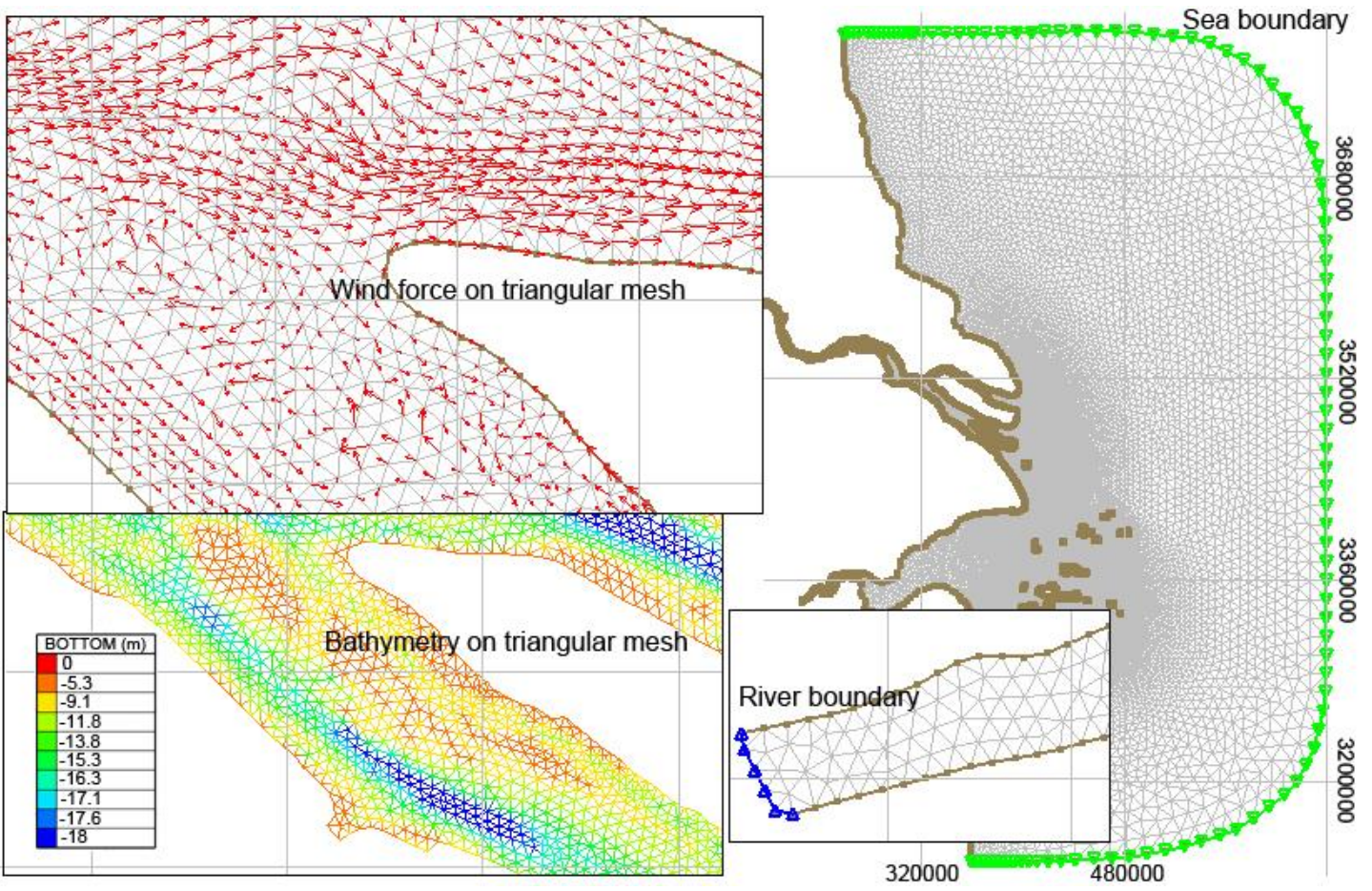

302

303

304

305

306

307

308

309

310

311

312

313

314

315

316

317

318

319

320

321

322

Figure 3. Model boundaries and illustration of model parameters on model grid (river boundary is at Datong)

The model domain covers the whole of the tidal Yangtze Estuary, extending from $117.5^{\circ} \mathrm{E}$ to $124.5^{\circ} \mathrm{E}$, and from $28^{\circ} \mathrm{N}$ to $34.5^{\circ} \mathrm{N}$. The large sea area is necessary for wave modeling in order to generate sufficient fetch (Figure 1a). An unstructured mesh is designed to follow the coastline, being relatively fine $(100-500 \mathrm{~m})$ in the channel and Yangtze river mouth, and coarser (2000-10000 m) offshore near the open boundaries (Figure 3). It has been shown previously (Zhang et al., 2016a; Cai et al., 2014) that even during the dry season, weak river inflow can significantly impact the residual water levels. Therefore fresh water at the Datong station was input using daily averaged river discharges (Figure 3). A 5-day spin-up period was used to ensure a sufficient period of interaction between river, tide and wave before the simulations were performed (Zhang et al., 2016b). Since waves are being generated locally (wind-waves) and can also propagate in from the ocean ("swell"), local wave generation is specified by applying wind from QuikSCAT over the grid, and the propagated waves are defined using ECMWF waves, which are imposed at the open ocean boundary of the TOMAWAC model. Exponential growth-type wind generation models and white capping were evaluated with the expressions due to Cavaleri and Rizzoli (1981) with default coefficients (EDF, 2011). Depth-induced wave breaking dissipation (Battjes and Janssen, 1978), bottom friction-induced energy dissipation (Hasselmann et al., 1973) and non-linear quadruplet interactions (Hasselmann and Hasselmann, 1985) was also activated using default settings. In the present application, the TOMAWAC model is run and coupled to the same grid as TELEMAC model, but different time steps were used. In TELEMAC a $30 \mathrm{~s}$ computation time step was used, whereas the time step for TOMAWAC was set to 10s. Information exchange between TELEMAC and TOMAWAC occurred at the same rate as the tide computation, every 30s.

Another process considered in the model is wetting and drying of shallow shoals and tidal flats 
over a tidal cycle. If cells become dry, the wind may trigger unphysical velocities as it becomes the only driving term in the equations (EDF, 2011). To avoid this, the influence of the wind is cancelled when the water depth decreases below a certain threshold value (0.2 $\mathrm{m}$ in this study). This means that the coefficient of wind influence for a dry cell is set to zero and excluded from the hydrodynamic calculation when all three velocity points of a cell surrounding a water level point are below the threshold level. If the water level rises above the threshold value, the cells become wet again, and the wind forces are reactivated.

\subsection{Scenarios modeled}

To interpret the influence of the hydrodynamics on sediment mobility and by inference bed morphology, we consider a number of scenarios that represent a set of realistic conditions. All the runs were configured with the same modeling setup, but different forcing conditions were used to test the relative importance of river, tide and wind-waves. Each scenario was run for 1 month after a warm up period of 5 days. Cases 1 and 2 are the validation runs. In both cases, boundaries were defined by real-time TPXO tide model, QuikSCAT atmospheric forcing and river inputs chosen to match the field measurement periods. For Case 1 the model was initialized on July 1, 2007 and after a model warm-up period, river inputs were introduced from July 7, 2007. For Case 2 the respective dates were June 1, 2016 and June 8, 2016. Simulations were run to the end of each month to include a period of spring and neap tide. To isolate the influence of wind-waves and river, a tide only condition (Case 3 ) was preformed with a spring-neap cycle consitent with a mean spring tide ( $4 \mathrm{~m}$ tidal range) and a mean neap tide ( $2 \mathrm{~m}$ tidal range) imposed at the seaward boundary with both the river flow and waves removed. A tide with runoff condition (Case 4) without atmospheric forcing and waves provides an assessment of river-tide interactions when river runoff is around wet season average $\left(35000 \mathrm{~m}^{3} / \mathrm{s}\right)$. Finally, 3 wave-current coupled runs were performed (Cases 5, 6 and 7) using average conditions for the summer and winter season with a spatially uniform and constant winds of $5 \mathrm{~m} / \mathrm{s}$ and $7 \mathrm{~m} / \mathrm{s}$ from SE $\left(100^{\circ}\right.$, landward) and NW $\left(350^{\circ}\right.$, seaward) direction, respectively, based on a statistical analysis of QuikSCAT wind data from 2002 to 2012. The incident waves specified along the open boundary for the summer season was a significant wave height of $0.6 \mathrm{~m}, 4.3 \mathrm{~s}$ wave period from the SE $\left(100^{\circ}\right)$, while for the winter season, a significant wave height of $0.7 \mathrm{~m}, 4.5 \mathrm{~s}$ wave period from the NW $\left(350^{\circ}\right)$ was used based on a statistical analysis of ECMWF wave data from 2002 to 2012. Table 1 summarizes the configurations for all the model runs.

Table1 Summary of modeled scenarios presented in this paper.

\begin{tabular}{|l|l|l|l|l|}
\hline Case & Scenario & Tide & Runoff $\left(\mathrm{m}^{3} / \mathrm{s}\right)$ & Wind and wave \\
\hline 1 & July 1-31, 2007 & TPXO 7.2 model & Measure runoff & $\begin{array}{l}\text { Real-time QuikSCAT wind } \\
\text { and ECMWF wave }\end{array}$ \\
\hline 2 & $\begin{array}{l}\text { June 1-30, } \\
2016\end{array}$ & TPXO 7.2 model & Measure runoff & $\begin{array}{l}\text { Real-time QuikSCAT wind } \\
\text { and ECMWF wave }\end{array}$ \\
\hline 3 & Tide only case & $\begin{array}{l}\text { Mean spring tide } \\
\text { (4m range) /Mean } \\
\text { neap tide (2m } \\
\text { range) }\end{array}$ & 0 & 0 \\
\hline 4 & Tide with & Mean spring tide & Averaged wet & 0 \\
\hline
\end{tabular}




\begin{tabular}{|c|c|c|c|c|}
\hline & runoff case & $\begin{array}{l}\text { ( } 4 \mathrm{~m} \text { range) /Mean } \\
\text { neap tide }(2 \mathrm{~m} \\
\text { range) }\end{array}$ & season (35000) & \\
\hline 5 & $\begin{array}{l}\text { Typical summer } \\
\text { climate case }\end{array}$ & $\begin{array}{l}\text { Mean spring tide } \\
\text { ( } 4 \mathrm{~m} \text { range) /Mean } \\
\text { neap tide ( } 2 \mathrm{~m} \\
\text { range) }\end{array}$ & $\begin{array}{l}\text { Averaged wet } \\
\text { season (35000) }\end{array}$ & $\begin{array}{l}\text { Wind }(5 \mathrm{~m} / \mathrm{s} \text { landward wind) } \\
\text { and waves }\end{array}$ \\
\hline 6 & $\begin{array}{l}\text { Winter climate } \\
\text { with wet runoff } \\
\text { case }\end{array}$ & $\begin{array}{l}\text { Mean spring tide } \\
\text { ( } 4 \mathrm{~m} \text { range) /Mean } \\
\text { neap tide ( } 2 \mathrm{~m} \\
\text { range) }\end{array}$ & $\begin{array}{l}\text { Averaged wet } \\
\text { season (35000) }\end{array}$ & $\begin{array}{l}\text { Wind }(7 \mathrm{~m} / \mathrm{s} \text { seaward wind) } \\
\text { and waves }\end{array}$ \\
\hline 7 & $\begin{array}{l}\text { Typical winter } \\
\text { climate case }\end{array}$ & $\begin{array}{l}\text { Mean spring tide } \\
\text { (4m range) }\end{array}$ & $\begin{array}{l}\text { Averaged dry } \\
\text { season (15000) }\end{array}$ & $\begin{array}{l}\text { Wind }(7 \mathrm{~m} / \mathrm{s} \text { seaward wind) } \\
\text { and waves }\end{array}$ \\
\hline
\end{tabular}

\subsection{Bottom shear stress}

The spatial and temporal variation of BSS over a tidal cycle in two dimensions is calculated analytically using the method proposed by Soulsby and Clarke (2005), see also Malarkey and Davies (2012). The resultant total BSS $\left(\tau_{c w}, \mathrm{~Pa}\right)$ is expressed as:

$$
\tau_{c w}=\sqrt{\tau_{\mathrm{c}}^{2}+2 \tau_{\mathrm{c}} \tau_{\mathrm{w}}|\cos \varphi|+\tau_{\mathrm{w}}^{2}}
$$

where $\tau_{c}=C_{D} U^{2}$ is the current-along kinematic BSS, $C_{D}=\frac{\kappa^{2}}{\log ^{2}\left(\frac{h}{r_{0} e}\right)}$ is the drag coefficient for the current along (log is to the base e), $\tau_{w}=f_{w} u_{w}^{2} / 2$ is the wave orbital BSS, $f_{w}=1.39\left(a_{w} /\right.$ $\left.\mathrm{r}_{0}\right)^{-0.52}$ is the friction factor for wave alone and $\mathrm{a}_{\mathrm{w}}=\mathrm{u}_{\mathrm{w}} / \omega$.

The inputs required to calculate BSS are the depth-averaged current (U), near bed wave velocity amplitude $\left(\mathrm{u}_{\mathrm{w}}\right)$, wave-current angle $(\varphi)$, and water depth $(\mathrm{h})$. These are provided for various scenarios modeled, as defined in the Notation. The vector of tidal BSS was subtracted from the combined vector BSS, leaving the non-tidal BSS components of river-driven BSS and wave-driven BSS. However, because tidal and non-tidal components may add or subtract based on direction, scalars will not sum to the total. Therefore, the river component of stress (Figure 10c) and wave component of stress (Figure 10f) in the absence of tidal currents were only estimated by taking the scalar differences. Consequently, they include the non-linear interactions and only provide an approximate estimation. Analyzing the components of stress in this manner allows for the relative magnitude of contributions from river, tide and waves to be assessed.

Since most of the river-born sediment is composed of silt and clay $\left(D_{50}=27 \mu \mathrm{m}\right)$, half of which settles in the river mouth area (Chen et al., 1985), the Critical Stress Thresholds (CST) for cohesive bed sediment mixtures were calculated with median grain size $D_{50}$ set to $27 \mu \mathrm{m}$. The bed roughness $\left(r_{0}\right)$ used in calculating bottom stress across the mouth-bar was also set to $D_{50}$. The estimation of critical erosion velocity and CST is formulated as (Du et al., 2010; Luan et al., 2017):

$$
\begin{gathered}
\mathrm{u}_{\mathrm{ce}}=\left(\frac{\mathrm{h}}{\mathrm{D}_{50}}\right)^{0.14}\left(\alpha_{1} \mathrm{D}_{50} \frac{\rho_{s}-\rho_{w}}{\rho_{w}}+\alpha_{2} \frac{10+h}{D_{50} 0.72}\right)^{0.5} \\
\operatorname{CST}=K_{e} \rho_{w}\left[u_{c e} /(2.5 \ln (11 h / \Lambda))\right]^{2}
\end{gathered}
$$

where the averaged depths of Chongming east shoal, Hengsha east shoal, Jiuduansha shoal, Nanhui east shoal, Channel of north delta and Channel of south delta were set to $-3.05 \mathrm{~m},-3.30 \mathrm{~m}$, 
$-2.11 m,-3.72 m,-7.74 m$ and $-8.48 m$, respectively. Other parameters are defined in the Notation. The CSTs of the above six locations are estimated to be $0.31,0.32,0.28,0.33,0.45$, and 0.48 $\mathrm{N} / \mathrm{m}^{2}$, respectively. These values are consistent with the CST values estimated by Luan et al. (2017), which ranges from 0.03 to $0.48 \mathrm{~N} / \mathrm{m}^{2}$ across the mouth-bar.

\subsection{Energy dissipation}

Use is made of the energy head density concept, developed for river systems (Richards, 1982), and extended to include the influence of tidal variations (Zhang et al., 2016a; Zhang et al., 2016b). The total energy head per unit width of water surface relative to a zero datum $\left(z_{0}\right)$ comprises of potential, kinetic and pressure energy density and can be written as:

$$
\dot{E}=\rho_{\mathrm{w}} \operatorname{gh}\left(\left|z_{w s}+\eta\right|+\frac{U^{2}}{2 g}\right)
$$

Integrating equation (8) over a tidal cycle, the total energy input per unit cell can be written as:

$$
E=\rho_{\mathrm{w}} \operatorname{gdxdy} \int_{0}^{T} \mathrm{~h}\left(\left|z_{w s}+\eta\right|+\frac{U^{2}}{2 g}\right) \mathrm{dt}
$$

The imported energy is dissipated by friction and sediment transport. Following the definition by Rodríguez-Iturbe et al. (1992), the energy dissipation per unit cell per second (van der Wegen et al., 2008) can be written as:

$$
\dot{\mathrm{P}}_{\text {cell }}=\underbrace{\mathrm{g} \frac{\mathrm{n}^{2}}{\sqrt[3]{\mathrm{R}}} \rho_{\mathrm{w}}\left(\mathrm{u}^{2}+\mathrm{v}^{2}\right)^{1.5} \mathrm{dxdy}}_{\dot{\mathrm{P}}_{\mathrm{bss}}}+\underbrace{\left(\rho_{\mathrm{s}}-\rho_{\mathrm{w}}\right) \mathrm{g}\left(\mathrm{S}_{\mathrm{x}}^{2}+\mathrm{S}_{\mathrm{y}}^{2}\right)^{0.5} \mathrm{dxdy}}_{\dot{\mathrm{P}}_{\mathrm{st}}}
$$

where, the first term on the right hand side is the energy dissipation per unit cell per second due to bottom shear stresses $\left(\mathrm{P}_{\mathrm{bss}}\right)$ and the second term on the right hand side is energy dissipation per unit cell per second due to sediment transport $\left(\mathrm{P}_{\mathrm{st}}\right)$. All other symbols used to describe energy dissipation are listed in the Notation.

Based on Engelund and Hansen (1967) and neglecting the sediment settling lag effect, the instantaneous total sediment transport $\left(S=\sqrt{S_{x}^{2}+S_{y}^{2}}\right)$, including suspended load and bed load is formulated as:

$$
S=\frac{0.05 U^{5}}{\sqrt{g} \kappa^{3} \Delta^{2} D_{50}}
$$

where $\kappa$ is friction parameter defined by $\sqrt[6]{\mathrm{h}} / \mathrm{n}\left(\mathrm{m}^{1 / 2} / \mathrm{s}\right)$. By combining equations (10) and (11) the energy dissipation, in 2 dimensions, over a complete tidal cycle is obtained. The hydraulic radius, $R$, is taken as the water depth, $R=h$, as the size of a grid cell $(200 \mathrm{~m})$ is much larger than the water depth $(\sim 10 \mathrm{~m})$. The reassembled equation of energy dissipation per unit cell over a complete tidal cycle is expressed as:

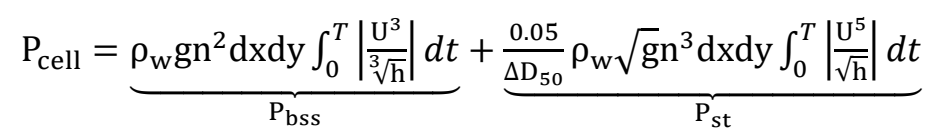

See Notation for definition of symbols.

\section{Results}

\subsection{Hydrodynamics modeling results and assessments}


To evaluate the numerical model performances, the depth-averaged velocities, free surfaces elevation and significant wave height observed within the estuary area were compared against the modeled values. After calibration, a constant Manning's coefficient $(n)$ of $0.014 \mathrm{sm}^{-1 / 3}$ is applied over the whole area in the TELEMAC model, representing of clayey silt bed material.
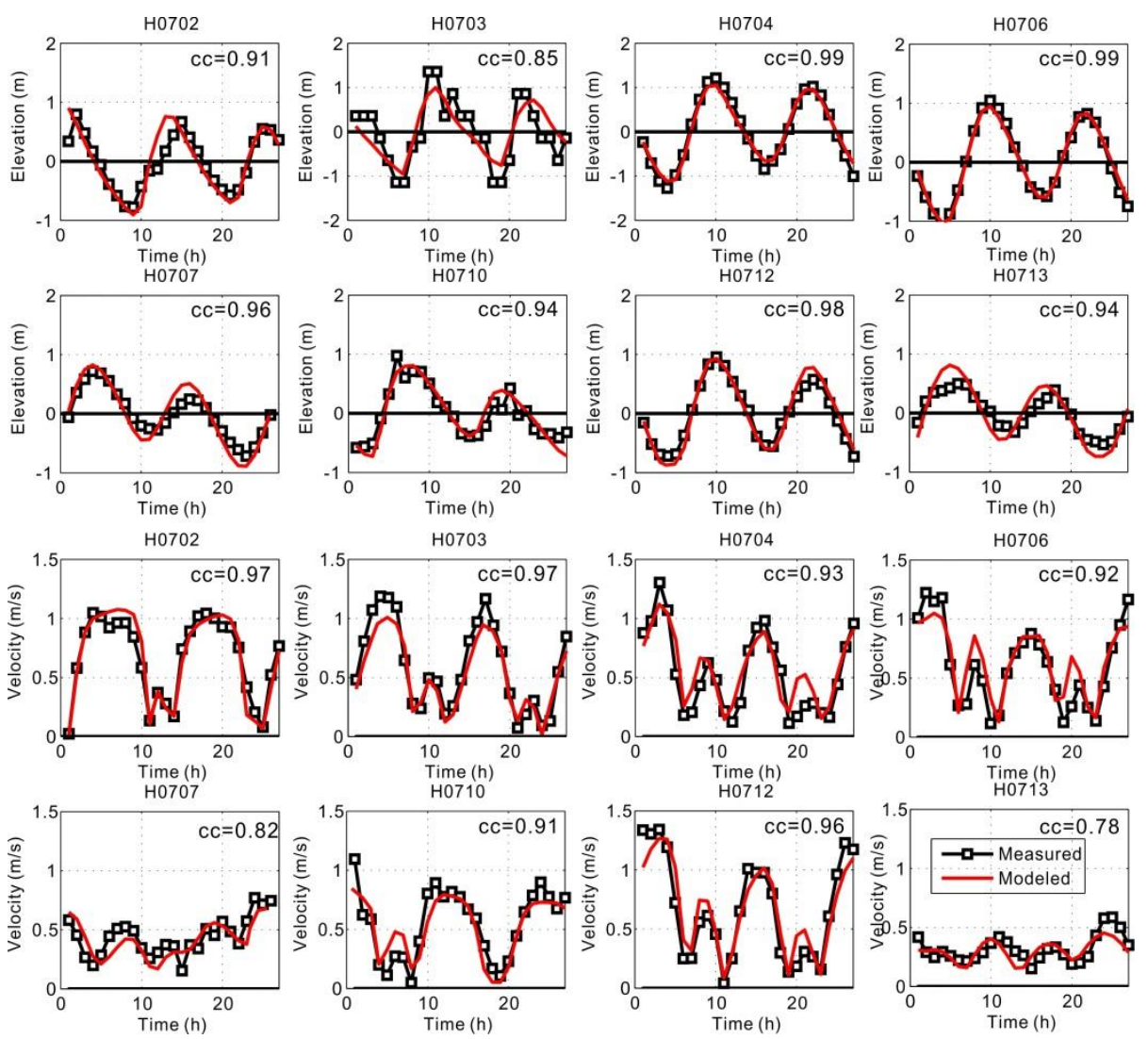

Figure 4 Observed and modeled time series of free-surface elevation (first and second rows) and depth averaged velocity (third and fourth rows) in the neap tide at stations H0702, H0703, H0704, H0706, H0712 (hours from 2007/7/22 7:00 to 2007/7/23 9:00, Beijing time), and stations H0707, H0710, H0713 (hours from 2007/7/23 13:00 to 2007/7/24 15:00, Beijing time) 

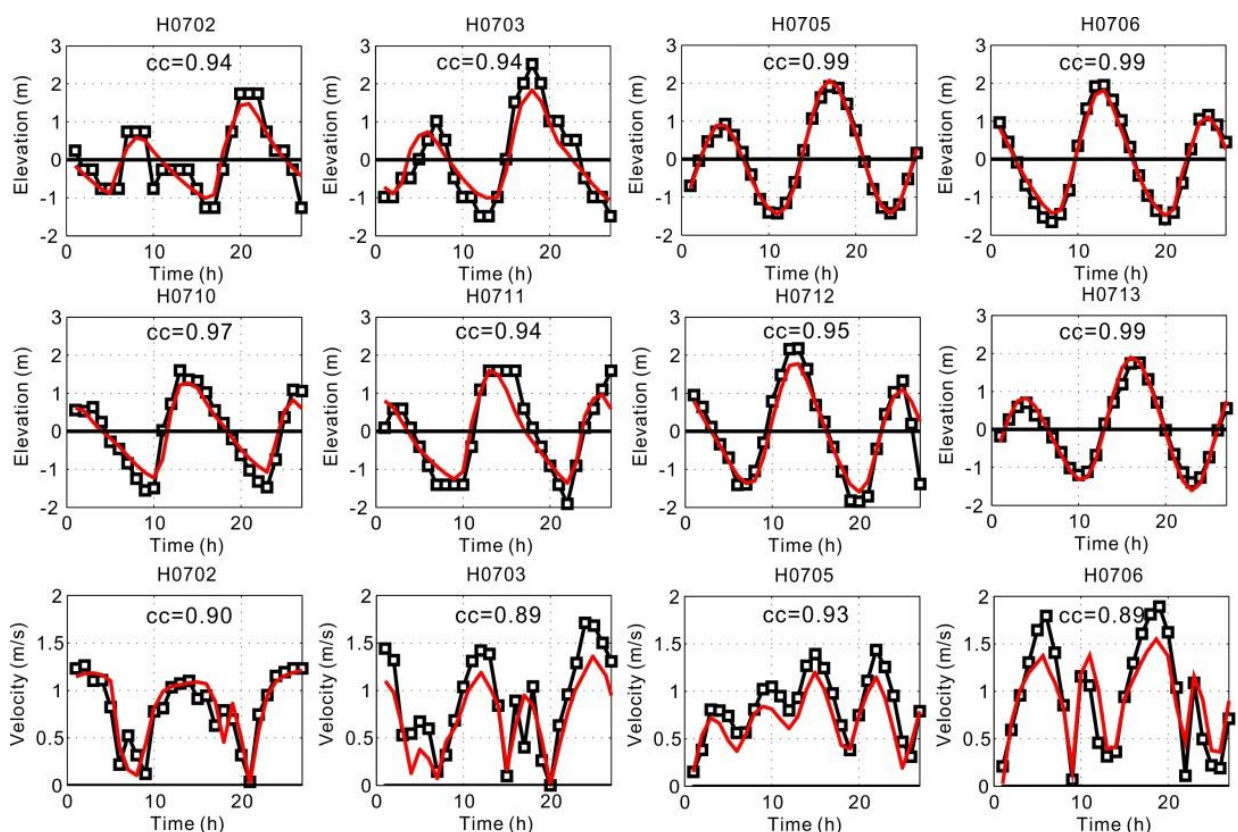

H0710
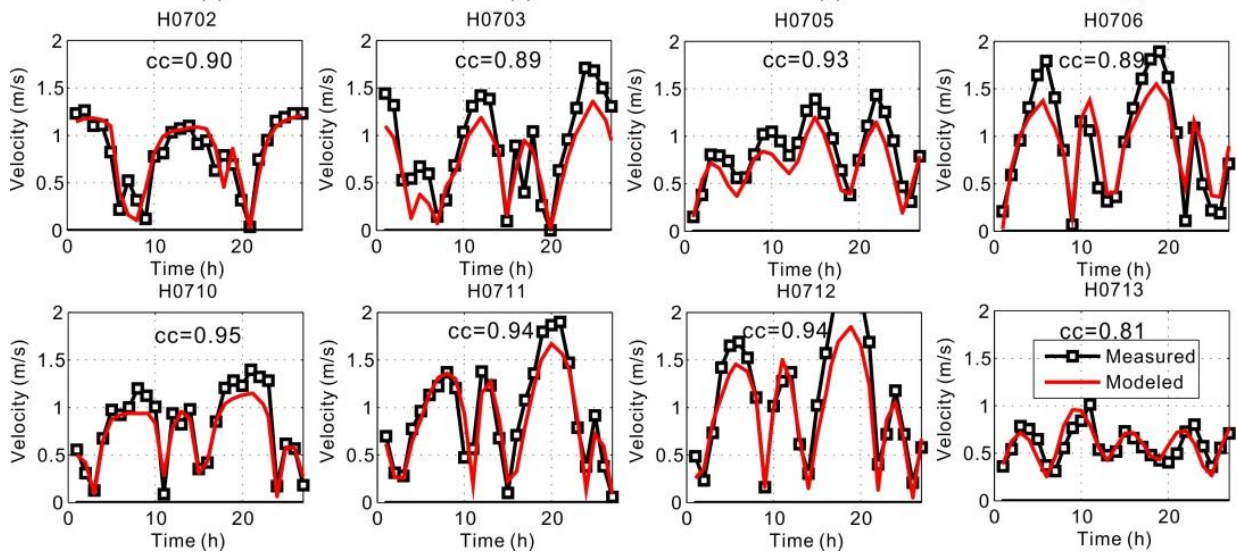

Figure 5. Observed and modeled time series of free-surface elevation (first and second rows) and depth averaged velocity (third and fourth rows) in the spring tide at stations H0702, H0703, H0705, H0713 (hours from 2007/7/29 7:00 to 2007/7/30 9:00, Beijing time), and stations H0706, H0710, H0711, H0712 (hours from 2007/7/30 12:00 to 2007/7/31 14:00, Beijing time)

A direct comparison between velocity and free surface time series from the model and the 10 observation stations (locations are shown in Figure 1) during 22-24 July, 2007 (representing a neap tide) is shown in Figure 4, and during 29-31 July, 2007 (representing a spring tide) is shown in Figure 5. It can be seen that the model reproduces the water level very well at all stations, with a correlation coefficient (cc) of about 0.96 . The reproduced velocities follow the observations satisfactorily, although the spring velocity is a little underestimated at some stations and some disagreements occur during the ebb maximum. The observed hydrodynamic parameters are clearly tidally dominated, with a strong tidal signal. 


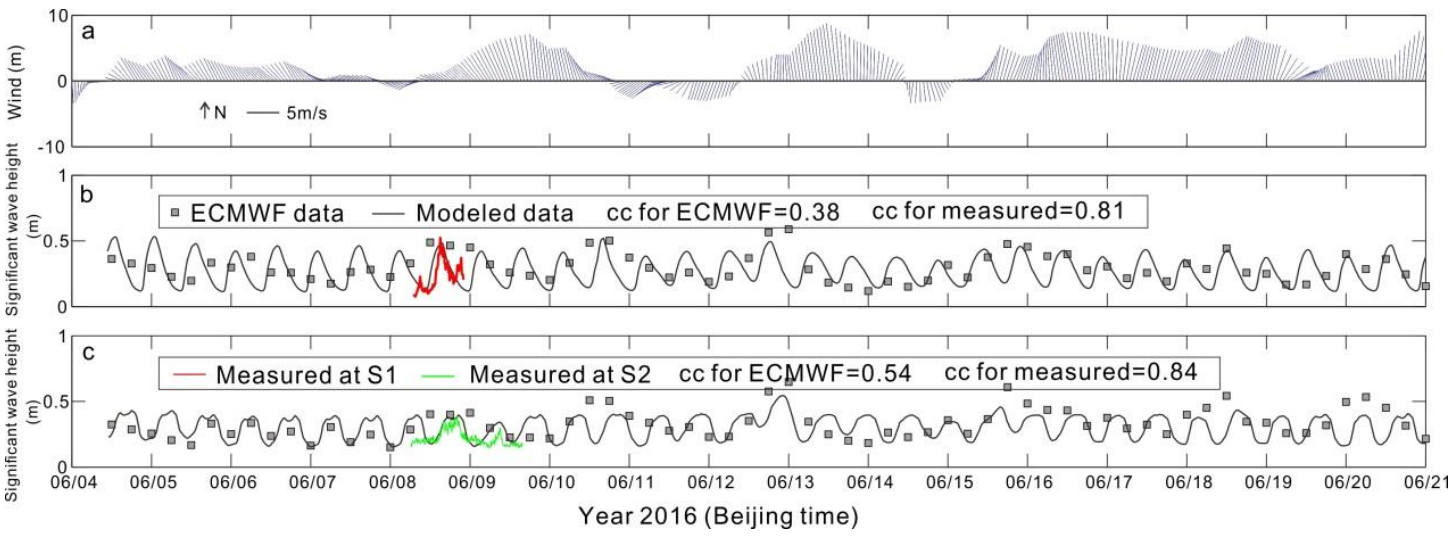

Figure 6. Time series comparison of significant wave height between modeled (TELEMAC-TOMAWAC), published (ECMWF) and observed (S1 - red line and S2 - green line) data at mouth-bar area. (a) is the wind vector near the measurement, (b) is the comparison at S1, (c) is the comparison at S2, the locations of S1 and S2 are shown in Figure 1.

453

Significant wave height was compared with published and in situ measurements at S1, located about $12.5 \mathrm{~km}$ off east Hengsha island and S2, located at the entrance of North Passage (Figure 1 and Figure 6). Both $\mathrm{S} 1$ and $\mathrm{S} 2$ are within the shallow water areas of the mouth-bar area, so that the modeling result is affected by both the bathymetry and the local wind forcing. The modeled wave height is in reasonable agreement with the measurements for the first peak of both S1 and S2. Overall, there is an under prediction of the significant wave height at S1 and over prediction at S2. The observed wave data only cover 1-2 days during the simulation period. The results of the wave model, in addition, were compared against the published ECMWF model results at the same location. The correlation coefficients between TELEMAC modeling and ECMWF ('cc for ECMWF' in Figure 6) and between TELEMAC modeling and measurement ('cc for measured' in Figure 6) indicate a better agreement between the TELEMAC results and measurements than with the ECMWF output. Overall, the model simulation was able to capture the magnitude but not the timing of fluctuations. The relatively lower model skill of the ECMWF data could either be due to limited resolution of the bathymetry in shallow waters, or the coarse resolution $(25 \mathrm{~km})$ applied at global scale. Despite the mentioned discrepancies, in general, the consistency between the simulation and in situ observations indicates that the local scale modeling provided by the coupled TELEMAC-TOMAWAC model is able to provide reasonable wave, current and free surface estimates over shallow shoals. 

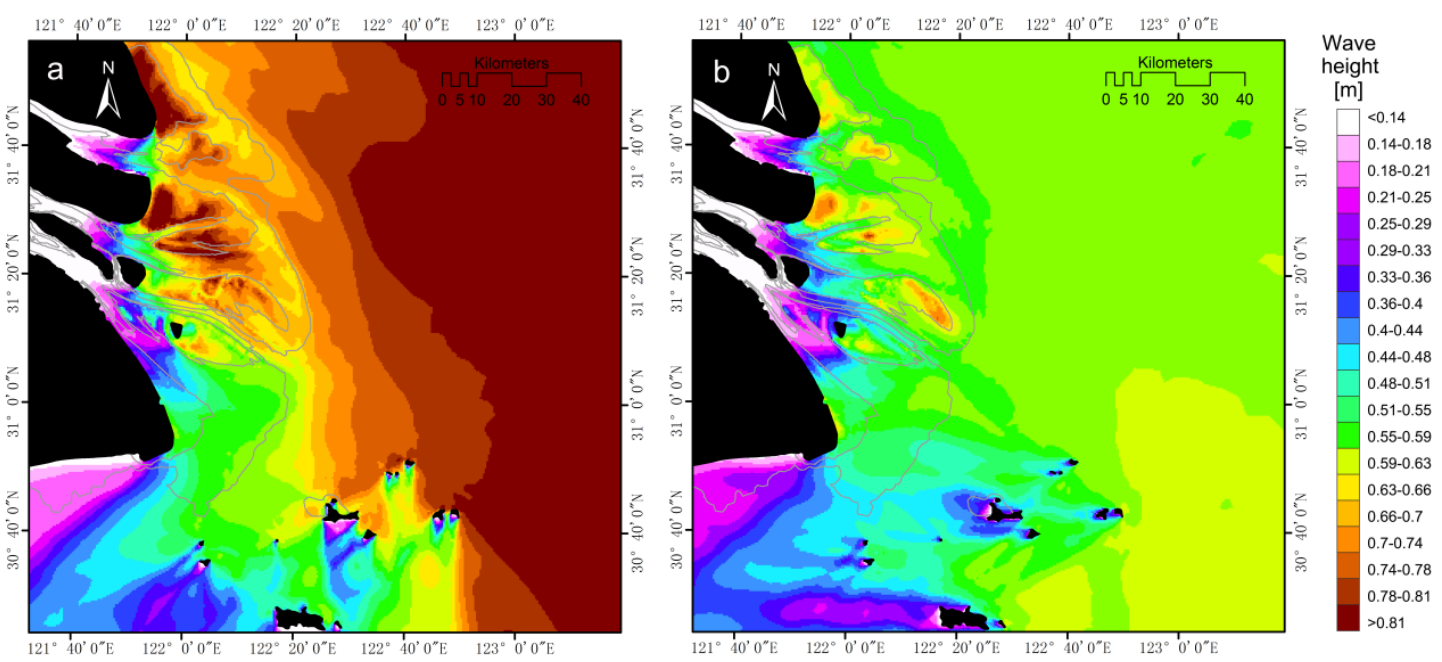

Figure 7. Maximum significant wave height over a tidal cycle around and off Yangtze Estuary during (a) typical winter season conditions (Case 7) and (b) typical summer season condition (Case 5).

The maximum significant wave height distribution, during averaged winter and summer season conditions, is shown in Figure 7. Offshore of the Yangtze Estuary, large waves (wave heights exceeding $0.8 \mathrm{~m}$ in winter season and about $0.7 \mathrm{~m}$ in summer season) are a direct response to the local wind forcing (Figure 2a,b) and show significant seasonal variation. Inshore, in contrast to the offshore area, it is evident that wave dissipation occurs, and it is evident that bathymetry modulation of wave parameters becomes stronger in the winter season. Near the shore, the wave height is reduced due to both bed friction and the shelter provide by the islands, which reduces the wind fetch. Within the river mouth, wave heights are attenuated to $<0.1 \mathrm{~m}$, while the mouth-bar area is an exception, where the computed significant wave heights increase. Larger waves are evident at the north part of the mouth-bar, whilst the south part of the mouth-bar is less exposed to wave activity.

\subsection{Hydrodynamics of river, tide and wave interactions}

The model results show that tidal current variation (mostly wave-current interaction) is more influenced by the seasonal changes in wind forcing than river discharge outside the estuary, whereas river-tide interaction is more significant within the mouth. Spatially, Stations 1\# to 12\# along the chainage from the river channel to the open sea (Figure 1), are selected to compare the variations. As indicated above, in the South Branch of the Yangtze Estuary the waves are mainly controlled by the external swell and the local wind from the SE during the summer. During this period, the modeled wave heights vary from $0.24 \mathrm{~m}$ outside of the mouth-bar, Station 12\#, to $0.1 \mathrm{~m}$ in the mouth-bar, Station $7 \#$, and to below $0.02 \mathrm{~m}$ inside the estuary, Station 3\# (black line of Figure 8b). However, when the wind veers to the NW during winter, the external swell is reduced but local wind-waves are increased, and the wave heights vary from $0.42 \mathrm{~m}$ outside of the mouth-bar, Station $12 \#$, to $0.16 \mathrm{~m}$ in the mouth-bar, Station 7\#, and to below $0.03 \mathrm{~m}$ inside the estuary, Station 3\# (green line of Figure $8 \mathrm{~b}$ ). Therefore, winter waves are on average higher than summer waves, and wave heights reduce upon propagation upstream. The sheltering by the islands, the shorter wind fetch within the estuary and large bottom friction of shallow shoals are considered the main factors that prevent the atmospheric forcing having a 
greater influence inside the mouth. Contrary to the wind affect, the influence of the river (river-tide interaction) is limited to the inner estuary (upstream of Station 4\#), even during summer wet season conditions, where the river mouth expands (Figure 1) and flow diffuses, as indicated by comparing the tide only condition (red line) and tide with river condition (yellow line) in Figure $8 \mathrm{c}$,d. Strong river discharge raises water level gradients ( $\sim 0.4 \mathrm{~m}$ at Xuliujing during wet season) and generates intense currents near the surface (observation from 3D model results). These changes could potentially have a greater effect on surface waves. However, as the wave heights are low within the river mouth, the river-wave interaction remains relatively minor.
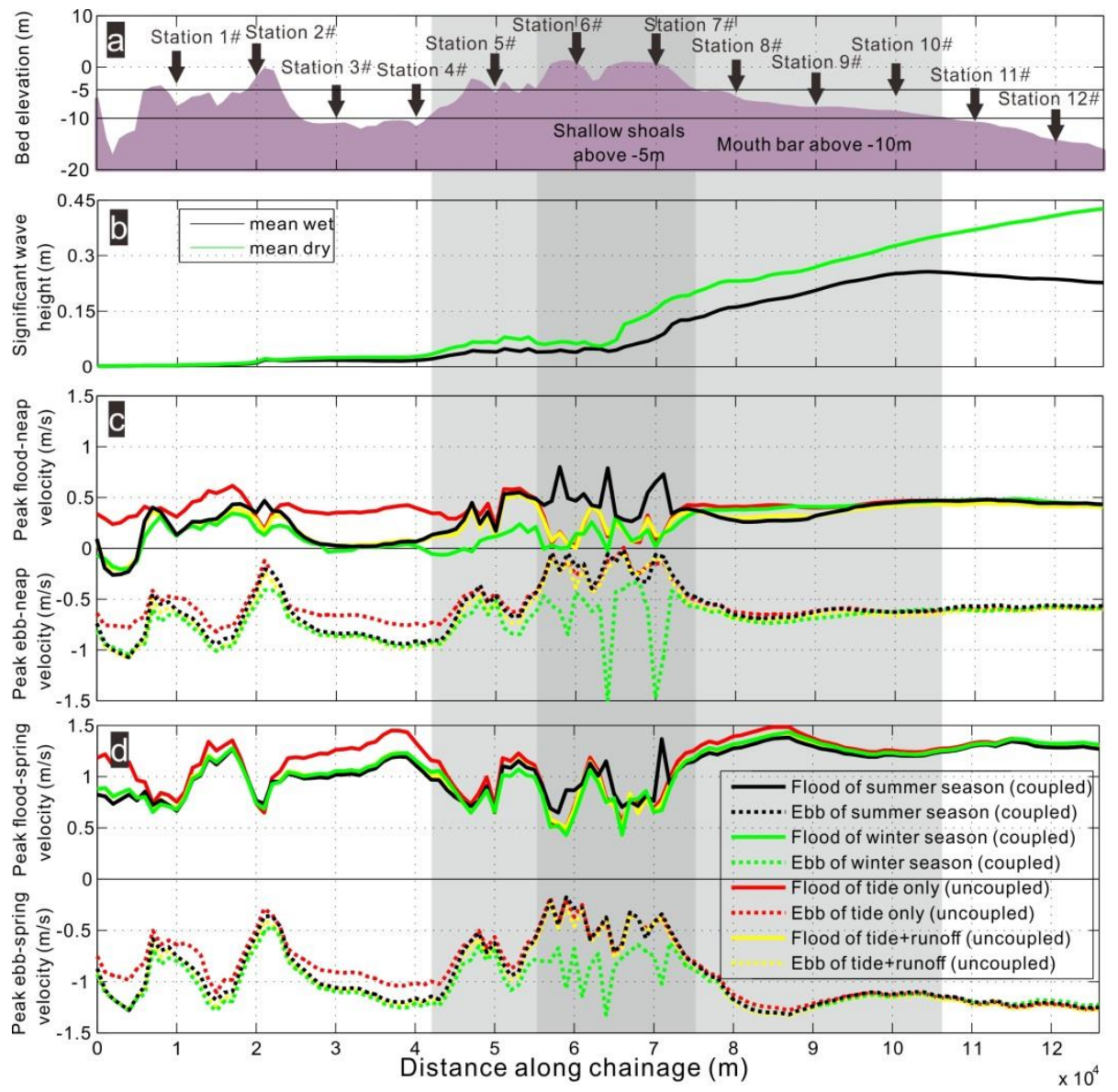

Figure 8. Variations along the section defined by chainage distances in Figure 1: (a) profile of bed elevation; (b) significant wave height for wet and dry season river flows; the comparison of amplitudes of the depth-averaged current velocity during flood and ebb process of a neap tide (c) and spring tide (d), with red line: tide only condition (Case 3), yellow line: tide with wet season runoff (Case 4), as well as wave-current coupled conditions for black line: typical summer climate condition (Case 5) and green line: winter climate with wet season runoff condition (Case 6).

Further seaward, outside the mouth, wind-waves are observed to have a noticeable effect on the tidal current upon reaching the mouth-bar, by comparison of the coupled and uncoupled wave-current results in Figure $8 \mathrm{c}$, d. Typically, significant wave-current interaction occurs in regions with strong currents over shallow shoals. The largest interactions occur near the mouth-bar 42-107km (Stations $4 \#$ to 10\#), where the wind-induced waves show the most obvious impact, especially in the shallow shoals above $-5 \mathrm{~m}$ (Station $6 \#$ and Station 7\#), where peak velocities show notable fluctuations. The effect decreases gradually as the hydraulic depth 
increases seaward. Generally, wave-current interaction is greatly affected by the propagation directions of wave and current. During summer climate conditions, the wind is southeasterly (blowing from ocean to land), therefore the depth-averaged peak velocities over the shallow shoals above $-5 \mathrm{~m}$ are enhanced by the wind during the flood tide (black solid lines of Figure $8 \mathrm{c}, \mathrm{d}$ ) and opposed (and weakened) by the depth-averaged peak velocities during the ebb tide (black dotted lines of Figure $8 \mathrm{c}, \mathrm{d}$ ). The return current converges in the deeper channels between the shallow shoals and therefore enhances peak velocities against the wind and slows peak velocities with the wind as identified between 75 and $106 \mathrm{~km}$ (Stations $7 \#$ to $10 \#$ and black solid lines in Figure $8 \mathrm{c}, \mathrm{d}$ ). Under winter climate conditions, the wind is reversed and therefore the effect is also reversed. The peak flood velocity during neap tide increases significantly for the summer climate condition but decreases greatly for the winter climate condition in the areas of shallow shoals, with an increase of $0.35 \mathrm{~m} / \mathrm{s}$ (140\% relative to the tide only condition (toc)) and a decrease of $0.1 \mathrm{~m} / \mathrm{s}$ ( $42 \%$ relative to toc) on average in the area between 55 and $75 \mathrm{~km}$ over the shallow shoals above $-5 \mathrm{~m}$ (black solid line and green solid line of Figure $8 \mathrm{c}$ ). In contrast, the peak ebb velocity during neap tide decreases slightly for the summer climate condition but increases significantly for the winter climate condition, with a maximum decrease no more than $0.03 \mathrm{~m} / \mathrm{s}(9 \%$ relative to toc) and a maximum increase up to $0.41 \mathrm{~m} / \mathrm{s}$ (133\% relative to toc) as a result of $\mathrm{WCl}$ (black dotted line and green dotted line of Figure $8 \mathrm{c}$ ). The changes during spring tide show similar trends, although not as significant (Figure 8d). Beyond the mouth-bar area (107 km away to the open boundary) the four cases of peak flow curves are superposed, reflecting the fact that the depth averaged wave-tide interaction and river-tide interaction have less impact. Therefore, in the following sections, evaluation of river-tide-wave effect focuses on the mouth-bar area above $-10 m$, shallow shoals above $-5 \mathrm{~m}$ and the channels in between. For this analysis, the mouth-bar is divided into north and south delta, and the shallow shoals are described as Chongming east shoal, Hengsha east shoal, Jiuduansha shoal and Nanhui east shoal with deep channels in between (Figure 1b).
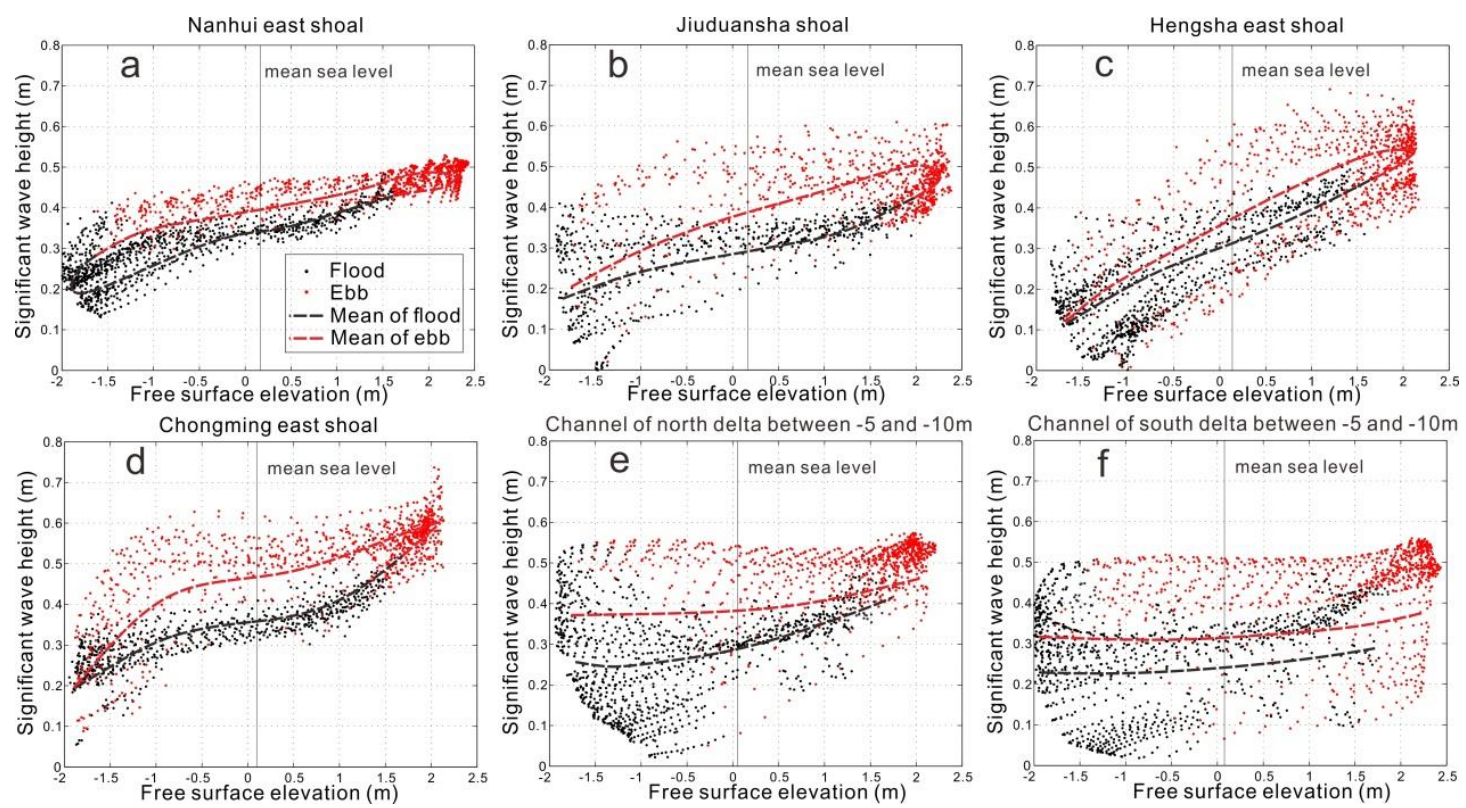

Figure 9. Scatter plot of significant wave height against free surface elevation for shallow shoals of Nanhui east, Jiuduansha, Hengsha east, Chongming east and the north and south deeper 
Wind-wave heights at the mouth-bar are modulated by tidal stage (Bolaños et al., 2014). Changes of hydraulic depth due to the tide lead to changes in ambient current, which potentially changes the effect of bottom friction, and therefore in turn leads to changes in wave penetration and propagation. This temporal influence of tide on wave is illustrated in Figure 9, which shows the relation of significant wave height to free surface elevation at the mouth-bar over a tidal cycle for both shallow shoals (Chongming east shoal, Hengsha east shoal, Jiuduansha shoal and Nanhui east shoal) and deep channels in typical summer wind conditions. The significant wave heights show periodic fluctuation with the tidal stage. During low water, wave propagation is subject to increased bed friction, producing shoaling, refraction or wave breaking, and resulting in more energy dissipation, especially in the shallow shoals where wave heights clearly decrease when water levels are reduced (Figure 9 a, b, $c$ and d). While in the deeper channels (Figure 9e, f) waves locally generated by the wind are less influenced by BSS and thus waves are less restricted by tidal elevation. Significant wave height is also potentially influenced by the propagation directions of ambient current and wave in both seasons. Take the summer season for example (Figure 9), some clustering can be identified during flood and ebb processes due to the modification of following and opposing current effect on waves generated by southeasterly wind, indicating a decrease/increase in height when the waves propagate in a following/opposite ambient current. 

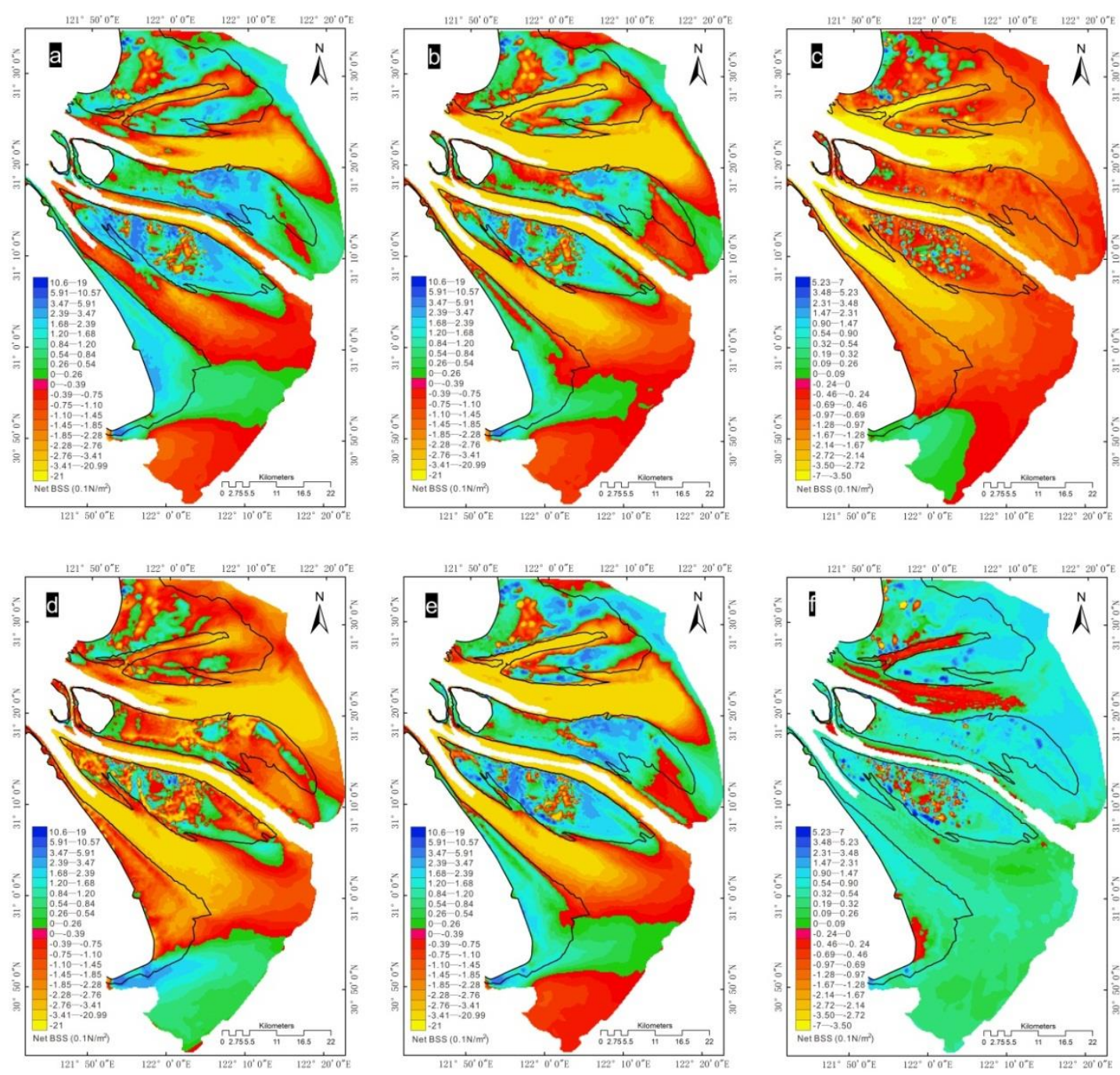

581

582

583

584

585

586

587

588

589

590

591

592

593

594

595

596

597

598

Figure 10. 2D distribution of time averaged BSS per unit area of bed over a tidal cycle $\left(\mathrm{N} / \mathrm{m}^{2}\right)$ for the scenarios of (a) tide only condition, Case 3, (b) tide with wet season runoff condition, Case 4 (c) wet season runoff only condition (i.e. b-a), (d) typical winter climate condition, Case 7 and (e) typical summer climate condition, Case 5, (f) summer wind-wave only condition (i.e. e-b). Positive BSS indicates the net value is in a landward direction, negative BSS indicates the net value is in a seaward direction. Solid black lines show the $-5 m$ contour lines. Note that a different scale is used for the scenario plots (a), (b), (d) and (e) and the difference plots (c) and (f).

The model output provides tide and wave fields, which can be used to examine the spatial variation of BSS for the different scenarios (based on equation 5). BSS is an important indicator of potential bottom sediment mobility, which can be related to morphological evolution. The simplified scenarios of tide only (Figure 10a), tide with wet season runoff (Figure 10b), and the wave-river-tide simulations for the winter season (Figure 10d) and summer season (Figure 10e) can be used to examine the net effect of seasonality. The difference in net BSS between scenarios is shown in Figure 10c for the tide with averaged wet season runoff (Figure 10b) and tide only (Figure 10a), indicating the effect of the high summer season runoff from the Changjiang river. Similarly, Figure $10 \mathrm{f}$ shows the effect of summer wind-waves by taking the difference in net BSS between scenarios for the typical summer climate (Figure 10e) and the 
typical summer runoff (Figure 10b).

For the tide only condition (Figure 10a), the positive tidal averaged BSS was found in bands of varying width over shallow shoals, including Chongming east shoal, Hengsha east shoal, Jiuduansha shoal and Nanhui east shoal. In contrast, negative net BSS occurred in the channels between the shoals and the intensity of stress forcing and mobility increased towards the thalweg, including the North Branch, North Passage and South Passage. The larger velocities and shear stresses occur in the channels, while shallow shoals are relatively quiescent and the patterns are relatively chaotic. The shallow shoals are distinguished from the mouth-bar area by the $-5 \mathrm{~m}$ contour and the positive net BSS over the shoals is seen to give way to negative values, as the water depths increase. Tide-driven currents influence the BSS out to water depths below $-10 \mathrm{~m}$ (Figure 10a). River-discharge reinforces the effect of negative BSS in deep channels, but only weakens the positive stress distribution over the shallow shoals to a limited degree (Figure 10c). The BSS from waves and currents shows significant variation over the shallow shoals due to the seasonal winds effect; where the high frequency orbital wind-waves were capable of penetrating to shallower depths (Figure $10 \mathrm{~d}$ and e). The seasonal means were composites of the summer and winter patterns. In winter, negative BSS is dominant over most of the mouth-bar with contributions from returned tidal flow, river flow (Figure 10c) and northwesterly wind-driven currents. The latter reflecting the observed correlation between wave direction and local winds (Figure 2). In summer, the wind goes round to the southeast and as result the positive BSS dominates over the shallow shoals and negative BSS is constrained to the deep channels.

The potential contribution of tide, river and wind-waves to sediment mobility and transport can also be inferred from Figure 10, based on the BSS distribution. For the tide only scenario (Figure 10a), BSS in shallower regions of the mouth-bar were relatively quiescent, with weaker stress forcing less able to initiate significant mobility, at around $-5 m$ the net BSS shows minimum where positive stresses switch to negatives. Conversely, along the channel to the thalwegs below $-5 \mathrm{~m}$, a band of strong net BSS resulted in higher mobility of the coarser sediment texture located there, with significant stress values becoming larger in the north part of delta and smaller in the south part of delta. Stress and mobility at the outer margin of the mouth-bar becomes smaller with the increase of depth. The coincidence of tidal BSS distribution and shoal-channel morphology pattern indicates the dominance of the tidal effect in shaping the mouth-bar. By contrast, the whole of the mouth-bar shows an overall negative BSS under just river flow (Figure 10c), with strong values within the deep channels and weak values on the shallow shoals and outer margin, indicating the export potential of river discharge. When the model is forced with a seasonal monsoon climate, there is a clear contrast between the responses of BSS patterns to the prevailing south-easterly summer wind and prevailing north-westerly winter wind and the resultant wave conditions (Figure 10d, e). Under the influence of summer wind-waves the whole of the mouth-bar shows a positive net BSS, with more intensive values in the north delta and less intensive values in the south delta but a relatively chaotic pattern (Figure 10f). Such effects are apt to trap more sediment to the inner part of the mouth-bar, especially the north delta and arrest its offshore dispersal, indicating the storing feature of summer wind-waves. However, during winter all of the non-tidal stress (wind-waves and runoff) metrics change, as discussed above, and sedimentation becomes export dominant, countering the summer situation. 

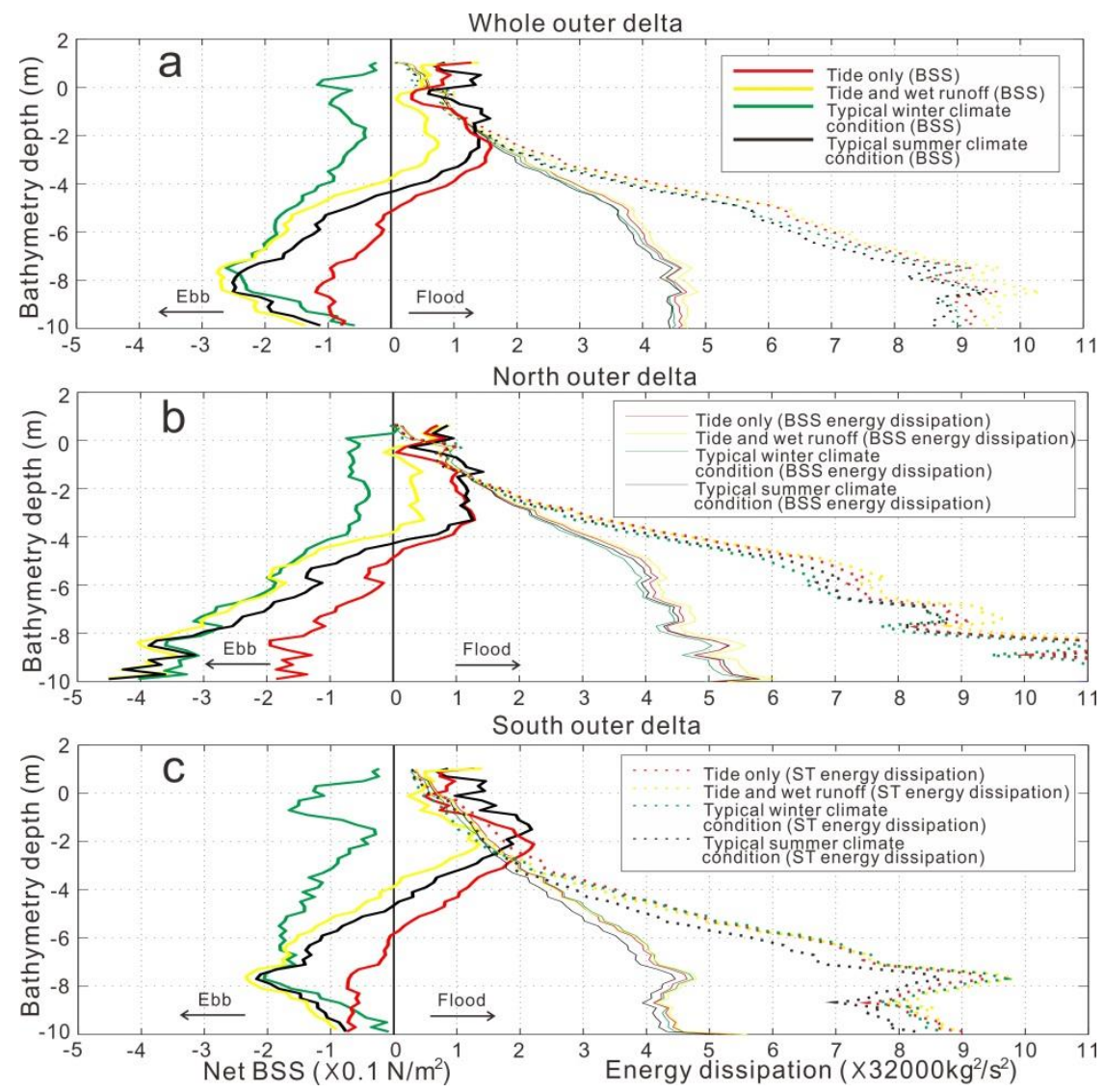

Figure 11 Comparison of spatial averaged net BSS and energy dissipation for (a) the whole delta, (b) the north outer delta and (c) the south outer delta. The 3 legends apply to all 3 plots, where (i) net BSS (solid thick), (ii) BSS energy dissipation (solid thin) and (iii) sediment transport, ST, dissipation (dotted thin) for tide only condition (red), tide with runoff (yellow), typical winter climate condition (green) and typical summer climate condition (black). Spatial averaging is taken over iso-depth and plotted as a function of depth, net BSS is shown in Figure 10 and energy dissipation is based on equation (12), the hypsometry profile is shown in Figure $1 \mathrm{~h}, \mathrm{l}, \mathrm{j}$. Flood and ebb-dominated residuals are positive and negative respectively.

To characterize the potential sediment transport patterns arising from tidal asymmetries in spatial and temporal dimensions, the averaged BSS over a tidal cycle relative to bathymetric depth and spatially averaged BSS relative to tidal stage are presented in Figure 11 . Since the study area is relatively small $(60 \mathrm{~km} \times 95 \mathrm{~km})$, and a representative tide was imposed, all examined parameters are simply averaged over time (a complete tidal cycle) and space (shallow shoals, deep channels and depth contour) rather than tracking the same tidal cycle for equal water surface elevation $(\eta)$, neglecting the small phase shift (and resulting sloping water level) across the domain.

As a supplement to Figure 10, Figure 11 shows clearly the BSS variation at different water depths. For the tide only condition (red lines) the maximum positive BSS was located around $-2 \mathrm{~m}$ and the maximum negative BSS was below $-8 \mathrm{~m}$, the switch between positive and negative BSS occurred around $-5 \mathrm{~m}$. Compared with the tide only scenario, the addition of river discharge (yellow lines) results in a significant increase of negative BSS in the deep channels but similar magnitudes to the tide only case over the shallow shoals, mostly because conveyance of the river discharge is 
mainly in the deep channels. Again, when compared with the tide-river scenario, the addition of wind-waves results in a more positive BSS in typical summer climate conditions (black lines) and more negative BSS in typical winter climate conditions (green lines) over the shallow shoals, with similar magnitudes to those experienced over the deep channels. This variation of net BSS over the shallow shoals, relative to that in the deep channels, is mostly due to the limited penetration of waves, while the shifting to be more positive (negative) on shallow shoals during summer (winter) is mostly due to seasonal wind effects. During landward summer winds, the wave-current interaction identified in Figure $8 c$ and $d$ occurs, and therefore the wind-wave enhances flow velocities over the shallow shoals during the flood tide (positive) and opposes (and slows) flow velocities during ebb tide (negative), which results in a more positive net BSS over a tidal cycle. The return current converges and flows in the deep channels, enhancing depth-averaged velocities against the wind and weakening depth-averaged velocities with the wind. This tends to decrease net BSS over a tidal cycle in the deeper areas. Under the more seaward winter wind, the effect is reversed and is reflected in the net BSS.

Channels deeper than $-5 \mathrm{~m}$ are less influenced by wind-wave orbital velocities, so seasonal changes in wind direction has very little influence on BSS and as a result, the seasonal sediment transport in this region is strongly seaward, dominated by the river and river-tide interaction and associated patterns of tidal asymmetry. The variation of energy dissipation due to BSS and sediment transport (ST) with hypsometric depth over the mouth-bar region also demonstrates transport dominance over BSS in this region (Figure 11). BSS energy dissipation and ST energy dissipation are small and have similar magnitudes over the shallow shoals, however in the deep channels the part due to ST increases significantly. A closer analysis of equation (12) shows that, ST energy dissipation is more influenced by the water depth and the velocity magnitude than BSS term, in which the velocity parameter is the more dominant factor. Consequently, the channels which are not only deep but also convey much of the flow, perform like corridors of water and sediment, dissipating most of the energy by sediment transport. This is almost double the magnitude of energy dissipation due to BSS, when water depths are greater than 6 or $7 \mathrm{~m}$.

\subsubsection{Potential sediment mobility (temporally variability) of tide only condition}



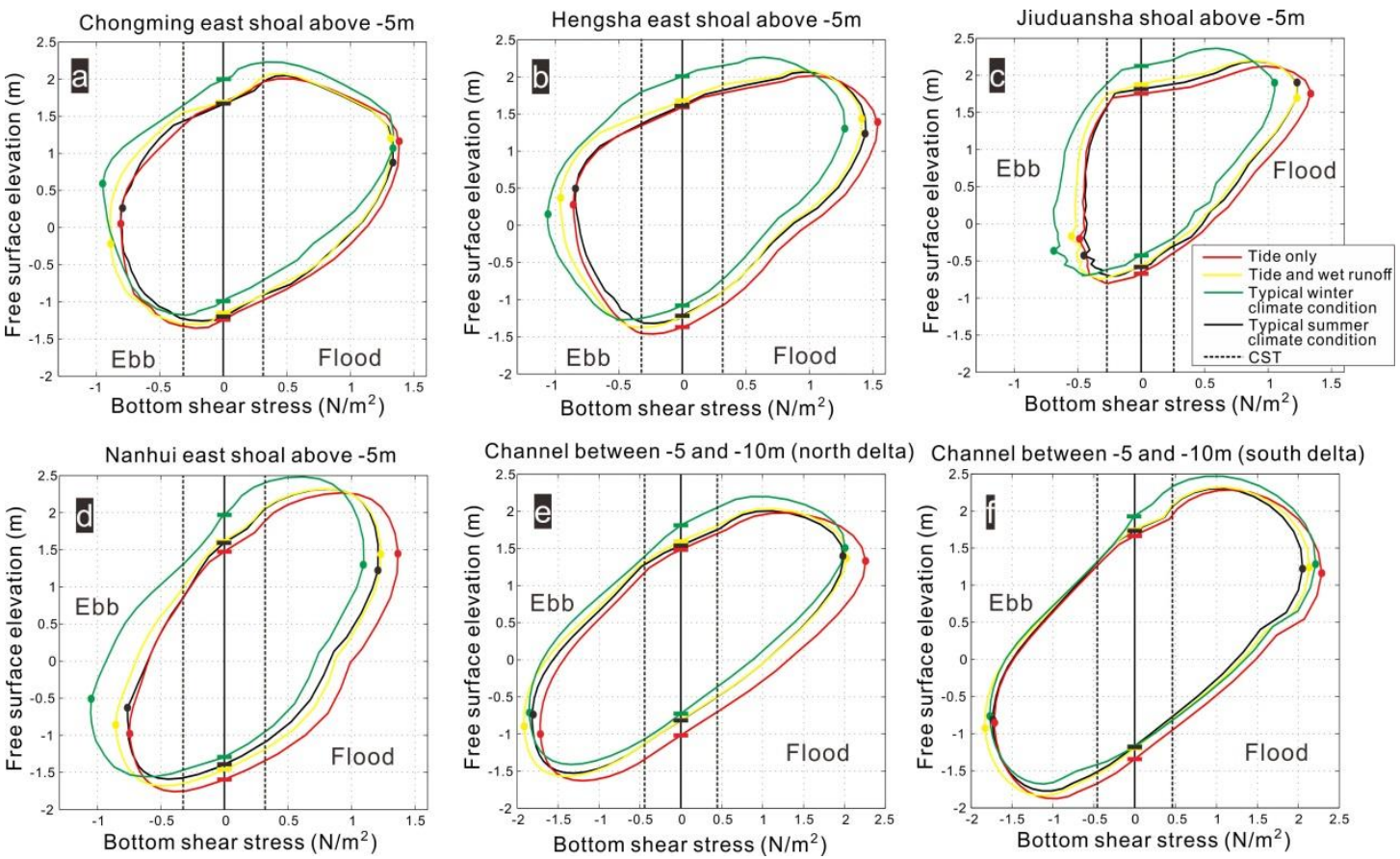

697

698

699

700

701

702

703

704

705

706

707

708

709

710

711

712

713

714

715

716

717

718

719

720

721

722

723

Figure 12. BSS relationship with tidal stage. Instantaneous BSS variation averaged over the shoals and channels is plotted as a function of water level over a complete tidal cycle, with the Critical Stress Thresholds (CST) marked with a dashed vertical line. Spatially averaging is performed over (a) Chongming ease shoal, (b) Hengsha east shoal, (c) Jiuduansha shoal, (d) Nanhui east shoal, (e) Channel of north delta and (f) Channel of south delta. Note the different $x$-axis scale between shallow shoals and deep channels. Flood and ebb-dominated residuals are positive and negative respectively. See text for details of the averaging technique.

To study the effect of BSS asymmetry over a tidal cycle, and the potential influence on morphology evolution, the tide only condition was taken as an example (red line in Figure 12). Spatially, the shallow shoals are classified as flood dominant and the deep channels are classified as ebb dominant, as discussed above. This classification is clearly demonstrated by observing the net BSS distribution with water depth (Figure 11a), where the flood (positive) stress in the north delta switches to negative (ebb) at around $-4.5 \mathrm{~m}$ (Figure 11b) while in the south delta the switch occurs around $-6 \mathrm{~m}$ (Figure 11c). This relatively simple interpretation is complicated slightly by analyzing the different patterns of spatially averaged stress over the 4 shallow shoals and 2 deep channels at different tidal stage (Figure 12a, b, c, d, e and f), i.e. the asymmetry in the temporal dimension. Bathymetry depth above $-5 \mathrm{~m}$ is defined as the shallow shoals, where the dominance switches from ebb-dominant in the lower part of shallow shoals to flood-dominant in the higher part of shallow shoals (Figure $11 \mathrm{a}, \mathrm{b}$ and $\mathrm{c}$ ). Therefore, at lower tide levels (free surface elevation $<-0.54 \mathrm{~m}$ at Chongming east shoal, $<-0.24 \mathrm{~m}$ at Hengsha east shoal, $<0.13 \mathrm{~m}$ at Jiuduansha shoal and $<-0.82 \mathrm{~m}$ at Nanhui east shoal), only the lower part of shallow shoals are inundated (this is apparent from the hypsometry profiles in Figure $1 \mathrm{c}, \mathrm{d}$, e and f) and the overall shallow shoals become so shallow that the averaged stress is ebb dominant, but when the tidal stage reaches higher values, the shallow shoal averaged stress becomes flood-dominated (Figure $12 a, b, c$ and d). The region of deep channels show similar variations (Figure 12e and f), but the switch point of tidal stage is around $\sim 0 \mathrm{~m}(0.04 \mathrm{~m}$ for the north delta and $0.01 \mathrm{~m}$ for the south 
delta) and the ebb period becomes longer. The elliptic shape of BSS over a cycle indicates that the tide is transitional between standing and progressive conditions, and zero velocity (0 BSS) does not coincide with high water level. Furthermore the variation in timing of (absolute) maximum BSS (between 1.2 to $1.7 \mathrm{~m}$ during the flood and between 0.3 to $-1 \mathrm{~m}$ during the ebb) contributes to the asymmetry of flood dominance at higher tide levels and ebb dominance at lower tide levels over the shallow shoals. For the deep channels, although the pattern of BSS is similar to that measured over the shallow shoals, the timing of the peak BSS shows that the tidal wave is slightly more progressive than that on the shoals. The relatively small maximum (absolute) BSS of Jiuduansha shoal (Figure 12c) compared with other three shallow shoals (Figure $12 a, b$ and $d$ ) is due to the convex hypsometry shape of intertidal (Figure 1e), which tends to result in a decrease in the tidal prism and an increase in friction over the relatively shallower intertidal, as well as a fast decrease in depth-averaged velocities and average water depth, accompanied with an increase in water level and extent of the intertidal area flooded. While the intertidal of the other three shallow shoals show a more concave trend (Figrue $1 c$, $d$ and $f$ ).

Another characteristic of the elliptic BSS-stage plots is the relatively flat curvature at high and low slack tide (horizontal bars in Figure 12), which indicate a short slack duration over both the shallow shoal and deep channels. Therefore the entrained (disturbed) sediments have only a limited time to settle out when BSS is small (the estimated time over which the BSS falls below CST during slack water is $2.75 \mathrm{~h}, 2.25 \mathrm{~h}, 2 \mathrm{~h}, 2.5 \mathrm{~h}, 1.5 \mathrm{~h}$ and $2 \mathrm{~h}$ for tide only condition at the 6 locations, respectively in Figure 12). When BSS goes above CST the sediment is suspended and transport occurs. The bigger BSS in deep channels and relatively smaller BSS over the shallow shoals (notice the scale difference between deep channels and shallow shoals in Figure 12) will result in suspended sediment density gradients between them, and the potential direction of fine sediment transport is toward the shallow shoals due to diffusion (Friedrichs and Aubrey, 1996). The gradient difference is most obvious for the Jiuduansha shoal as discussed above, and helps explain why the Jiuduansha shoal was observed to be the fastest accretion region compared with other shallow shoals (Dai et al., 2015; Yang et al., 2000; Wei et al., 2016).

\subsubsection{Non-tidal (river and wave) effect}

The complexity of the BSS asymmetry pattern, for the tide only condition, is enhanced when river and wind-waves are included. This complexity is due to the additional barotropic gradient from river discharge (Kuang et al., 2017), the baroclinic influence of wind-waves (Bolaños et al., 2014) and the interactions with the changing bed friction due to intermittent flooding and drying of the intertidal areas. As revealed by the model simulation, the fresh water discharge has an obvious influence on the resultant tidal BSS asymmetry due to superposition of river current on tide current, resulting in a steady increase of ebb BSS in deep channels and a slightly decreased flood BSS on shallow shoals. Waves can contribute to the tidal BSS asymmetry through wave setup induced by radiation stresses (Dalyander et al., 2013b; Bolaños et al., 2014). This can increase or decrease the effective BSS felt by the mean flow on the following and opposing current. Therefore, variations in the BSS when non-tidal components (wind-waves and runoff) are included show similar patterns to the tide only condition (Figure 12) but with an overall displacement to the upper left, indicating a shift of asymmetry (in the temporal dimension) and a BSS transition to be more ebb dominant under increased river runoff condition and northeasterly 
winter wind-wave conditions, but more flood dominant under southeasterly summer wind-wave conditions. In the spatial dimension, the greatest flood asymmetry in BSS occurs at higher water levels than the greatest ebb asymmetry. Furthermore, the BSS is significantly greater in the deep channels than over the shallow shoals, indicating a shoreward decrease of suspended sediment concentration and transport under this gradient force, regardless of non-tidal influences.

Using BSS asymmetry to infer tidal sediment transport potential in the temporal dimension, suggests a seaward transport of sediment in channels and landward transport of sediment on shoals (Figure 12). The river discharge reinforces the overall exporting effect. However, the fine sediment transportation at slack water is mostly due to diffusion, and the potential direction is decided by the difference in BSS over the shallow shoals and deep channels with diffusion occurring towards areas of lower BSS on the shallow shoals. However, when wind-waves are included there are two interacting effects:

(i) a BSS asymmetry in the spatial dimension through differences in wave orbital velocities that transport sediment to less hydrodynamically active areas where it is deposited;

(ii) BSS asymmetry in the temporal dimension through wave-current interaction that result in net sediment transport due to net orbital velocity asymmetry.

The addition of wind-waves in this study did not change the nature of suspended sediment advection, since the oscillatory nature of the wave orbital velocities and BSS differences between shallow shoals and deep channels was not changed (Figure 12). The strong influence of the tide and river in mouth-bar is further demonstrated by the relatively weak wave BSS and ST energy dissipation (the difference of energy dissipation between tide only and other three cases in Figure 11 is due to non-tidal components, which is small). However, the combined effect of wave-current interaction results in the tidal asymmetry in the temporal dimension that when seaward tidal asymmetry exceeds diffusion effects at high tide, sediment transport will be in a seaward direction during winter, but in a landward direction under southeasterly summer wind-waves (Figure 11). Although the absolute wave effect is weak, seasonal winds are both persistent and from a very narrow directional sector, for each half of the year, and the cumulative wave effect is discernable over the shallow shoals, where the shear stress exhibits complete reversal in direction from winter to summer (Figure $10 \mathrm{~d}$ and e). As a result, wave-current interaction and the patterns of sediment transport have an obvious seasonal variation in direction under seasonal wind influence, indicating an offset of shallow shoal evolution between winter erosion and summer storing.

\section{Discussion}

BSS is the parameter we have used to infer potential morphology change. To understand the hydrodynamic mechanisms that influence mouth-bar evolution, a wave-current model, coupling TELEMAC-2D river-tide hydraulic module and TOMAWAC wind-wave propagation module was used. BSS was then calculated with the reproduced currents, water depth and wave amplitude. The analysis of the spatial and temporal variations in BSS, because of the interactions of river flow, tides and waves provides some useful insights into how the hydrodynamics influences the geomorphology of the Yangtze Estuary delta. As waves decay rapidly on reaching the inner river mouth, they are not considered to play an important role in shaping the morphology there. The main controlling hydrodynamic forces in that specific reach are thus determined by the river flow and tidal conditions, which have been analyzed numerically and analytically in previous work 
(Zhang et al., 2016a; Zhang et al., 2016b; Guo et al., 2014; Wang et al., 2013; Wang et al., 2008). However, the velocity is changed significantly over the shallow shoals of the mouth-bar when waves and currents (tide and river) are both present, so both the current and the wave induced BSS are important. The seasonal wave dynamics in the Yangtze Estuary is characterized by northwestward waves in the summer and southeastward waves in the winter, which may induce a seasonal conversion between erosion and deposition. Here we mainly discuss tidal asymmetry, wave disturbance and the interaction of the two on potential sediment mobility in the mouth-bar area.

\subsection{The effect of river, tide and waves}

Overall, the mouth-bar of the Yangtze Estuary is a relatively open area, where the estuary widens rapidly and the influence of the river diminishes. Whilst river discharge is characterized as a pervasive exporter of sediment, it is not considered to be the main shaping factor of mouth-bar morphology. The main factor on the development of shoal-channel pattern is the strong tidal propagation from East China Sea (Dai et al., 2015). Under tide only conditions (Figure 10a, Figure 11 red line) the net BSS over a tidal cycle is ebb-dominant in the deep channels and the lower part of shallow shoals, and flood dominant in the upper part of shallow shoals. The effect of temporal tidal asymmetry is to scour the sediment from the deep channels and move them away from the lower part of shallow shoals, contributing to the continued growth of shallow shoals (Hunt et al., 2015). Another tidal effect that reinforces the expanding shallow shoals is the spatial asymmetry of density gradients (due to the large BSS difference between shallow shoals and deep channels), resulting in diffusion of suspended sediment from deep channels to shallow shoals but not allowing the suspended sediment to settle down until nearly at high or low slack water. Hence, the temporal tidal asymmetry maintains and deepens the channels, while the spatial tidal asymmetry tends to reinforce the gradual growth of the shallow shoals.

Despite the importance of tidal sediment transport over the mouth-bar area, the ratio of energy dissipation between sediment transport (ST) and bottom shear stress (BSS) was found to be close to unity over the shallow shoals (Figure 11). From a hydrodynamic perspective, the Yangtze Estuary is river-tidally dominated because of the relatively large fresh water discharge and tidal effect on sediment mobility. This results in a good coincidence between shallow-channel patterns and BSS distribution for both tide only conditions and river-tide combined conditions in Figure 10a, b. However, seasonally wind-induced wave stresses were also high over the shallow shoals and the potential sediment transport ability shows significant variance between winter and summer climate conditions (Figure 10d, e). Therefore, wave stresses proved to be important to induce sediment mobility in the mouth-bar area. On one hand, with this shallow bathymetry the higher-frequency orbital wave current is capable of penetrating to shallow depths even at high tide, triggering significant increases of sediment re-suspension around slack water and keeping the sediments from deposition which would occur in the absence of wind-waves. The lack of deposition combined with flocculation (Guo and He, 2011) and tidal blocking (Gong et al., 2012; Kuang et al., 2017) is consistent with the observation of a Turbidity Maximum Zone (TMZ) in this area (Figure 13). On the other hand, the disturbed sediments are transported through tidal asymmetry arising from both the length of flood-ebb duration (asymmetry in temporal dimension) and sediment diffusion (asymmetry in spatial dimension). The addition of wind-waves in the model did not change the inferred pattern of suspended sediment diffusion in 
853

854

855

856

857

858

859

860

861

862

863

864

865

866

867

the spatial dimension, since the oscillatory nature of the wave orbital velocities and BSS differences between shallow shoals and deep channels was not changed. However, the combined effect of wave-current interactions results in BSS asymmetry in the temporal dimension that when seaward BSS asymmetry exceeds the diffusion effect at high tide, sediment transport will be in a seaward direction during winter, but changed to be in a landward direction when under the influence of southeasterly summer wind-waves.

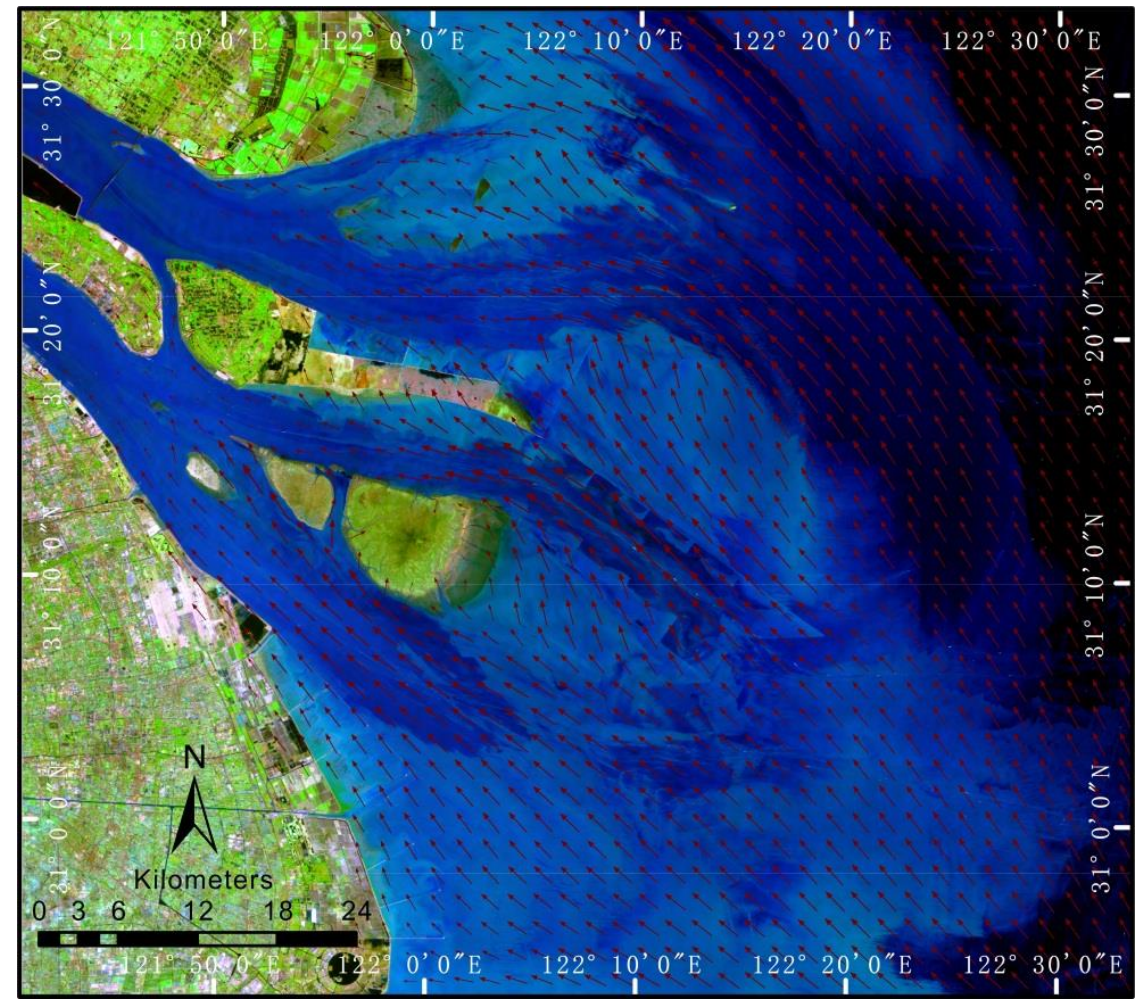

Figure 13. Turbidity Maximum Zone (TMZ) at the mouth-bar area and flood maximum velocity during summer season. The date of ETM image is on July 20, 2016 (http://glovis.usgs.gov/). Composite is with band 7, 5 and 3, which is most suitable for recognizing suspended sediment. Gray texture is of high SSC and blue texture is of low SSC. The whole mouth-bar is almost located within the TMZ.

\subsection{The stability of mouth-bar}

The stable development of shoal-channel patterns at the mouth-bar of Yangtze Estuary relies on morphological evolution over tidal cycles (short-term) and seasonal cycles (long-term). 


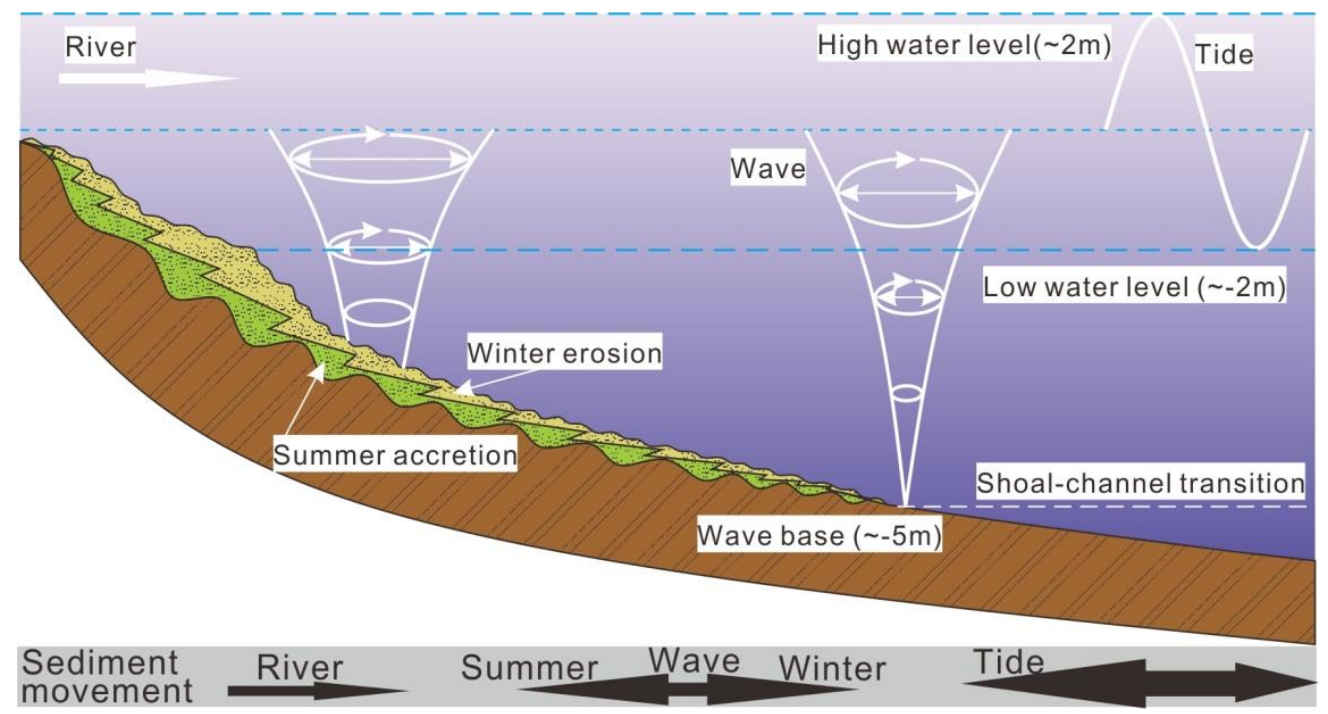

Figure 14. Diagram showing morphology response to hydrodynamics and sediment dynamics from river, tide and wave for both summer and winter seasons. The layers of winter erosion and summer accretion happen alternately, while the magnitude depends on the intensity of seasonal wind-waves, so after many years these two layers are mixed together.

\subsubsection{Development on tidal scale}

During a tidal cycle in a typical estuarine channel, larger flood tide velocities occur when the average depth is greater during the passage of the crest of the tidal wave (high water) than the trough (low water) (Friedrichs and Aubrey, 1988), resulting in flood dominance (i.e. the import and storing of sediment). With the inclusion of shallow shoals, which increase in height and area at the mouth-bar, channels in between are proportionally narrowed. Under tide only conditions, the inundated average depth is smaller at the crest of the tidal wave (over shoal flow) compared with the trough (channel flow), resulting in a slower propagation speed on the flood tide and a corresponding greater peak speed during the ebb tide, giving rise to ebb dominance (erosion and export of sediment). For a stable shoal-channel regime to exist, the sediment moved on the flood and ebb must balance so that there is no net sediment transport over a tidal cycle. Clearly this is not achieved by considering just the tidal influence.

Wind-wave generated currents have little direct influence on sedimentation in the channels of the mouth-bar due to the attenuation of wave orbital velocities in deeper water depths (Figure 14). However, the presence of wind-waves on the shoals increases the entrainment and transport of sediment over the shoals by reinforcing BSS $\left(\tau_{c}\right)$ through wave stirring and wave-current interaction. The effect of wave stirring at high tide (when the largest fetches exist) is more powerful for the more convex intertidal slope due to the shallowing of the intertidal region, allowing greater wave penetration. However, a more convex intertidal eventually becomes so shallow that it is only inundated for a brief time and so reduces the duration above Critical Stress Thresholds (CST). This was observed by comparing results for the Jiuduansha shoal with the other three shallow shoals (Figure 12). The interaction of these two factors indicates that there is a critical shallow shoal slope which is more likely to evolve to a stable profile shape. An over concave shape is likely to accrete and an over convex shape is likely to erode. Hence the combined influences of tide and wind-waves provide a mechanism that enables the shoal-channel morphology to adjust over the scale of a tidal cycle; as suggested by previous 


\subsubsection{Development on seasonal scale}

901 The results also suggest that there are periodic fluctuations in the development of the mouth-bar

902 on longer timescales than a tidal cycle. The seasonal signal demonstrated in Figures 10 and 11

903

904

905

906

907

908

909

910

911

912

913

914

915

916

917

918

919

920

921

922

923

924

925

926

927

928

929

930

931

932

933

934

935

936

937

938

939

940

941 clearly displays two important boundaries around $-5 m$ and $-2 m$. Firstly, the contrast between the response of the shallow shoals and deep channels to tide creates a stable boundary around the $-5 \mathrm{~m}$ contour line. No substantial change to tidal asymmetry occurs for seasonal varying river discharges, although seasonal wind modifies the tidal current in a different way either side of this boundary. Considering the relatively stable tidal dynamics of the East China Sea (Haigh et al., 2011), the variation of wind speed and direction, due to the regional East Asia Monsoon climate, is the driving force of seasonal changes in the magnitude and direction of wave-current interactions (Figure2, 8) and seems to control intrinsic seasonal cycles in erosion and deposition above the $-5 \mathrm{~m}$ contour. Secondly, the results semi-quantitatively show that with increasing distance offshore there is an increase in sediment supply, due to increased BSS energy, but also an increase in hydrodynamic ST energy (Figure 11). The significant increase in sediment accumulated in the zone around $-2 \mathrm{~m}$ during averaged summer climate conditions could not have occurred further shoreward, as shallow shoals are only inundated for short periods and with relatively small water depths (i.e. with a limited sediment supply). Neither could it have occurred further seaward where the hydrodynamic energy to transport sediment is greater. This implies that under averaged summer climate conditions, the area around $-2 m$ is most likely to accrete due to a balance between sediment supply and hydrodynamic conditions that transport sediment. However, during winter the whole of the mouth-bar is dominated by negative BSS and the frontal edge of the intertidal can be subjected to erosion, or may remain and begin to consolidate, depending on the frequency and intensity of episodic wave events (Kirby and Kirby, 2008). Therefore, during the summer, shallow shoals experience substantial accretion and during the winter the shallow shoals will return to an erosional profile and the annual cycle of seasonal accretion and erosion repeats itself, as shown in the conceptual model (Figure 14). Overall, the two contrasting processes, due to the interaction of the tide with summer and winter wind-waves, suggests that the behavior of the shallow shoals, switching from storing sediment in the summer to erosion over the winter, is dependent on the well-defined seasonal climate of the region. This implies that any changes in this pattern (e.g as a result of storm tracking or climate change) may alter the relative stability of the system.

Although the pattern of morphological evolution identified in the present study is only schematically inferred from BSS, the suggested seasonal variation on an annual timescale can be checked using the navigation maps for the area around Nanhui east shoal (red square frame in Figure 1b). The seasonal erosion (negative) and deposition (positive) indicated by calculating the averaged bathymetry change between consecutive maps in the time series is shown in Figure $1(\mathrm{k})$ and $1(\mathrm{I})$. Although the processes that lead to this periodic development maybe site specific and there are many other factors that may disturb this seasonal development, the available navigation maps do suggest that shallow shoals experience erosion during winter and accretion during summer i.e. they have a summer storing and winter erosion trend. Similarly, hydrographic observations and suspended-sediment measurements off the Yangtze Estuary (Milliman et al., 1985; Liu et al., 2010) revealed that $\sim 40 \%$ of the sediment load from river is deposited in the TMZ 
during the summer season, but much of it is re-suspended and carried seaward during winter. This result is also demonstrated using some limited observations by Zhu et al. (2014) at an exposed tidal flat on Nanhui Foreland. They concluded that onshore sea breezes result in sediment deposition and near-bed SSC increased to $>8 \mathrm{~kg} / \mathrm{m}^{3}$, while the offshore sea breezes results in sediment re-suspension and the near-bed SSC reduced to $<2 \mathrm{~kg} / \mathrm{m}^{3}$ over the measurement period. In fact, these findings are consistent with the results of observed tidal mudflats evolution in Bridgwater Bay of the Bristol Channel, UK (Kirby and Kirby, 2008) and with the observations at Peterstone Wentlooge on the north shore of the Severn Estuary (O Brien et al., 2000). They all demonstrated a persistent contribution of wind-driven flow to sediment mobility and a seasonal pattern of change on the tidal flat.

\subsubsection{Long-term stability}

The superposition of seasonal morphology behavior of the mouth-bar over years produces the inter-annual development trend. In the Yangtze Estuary, the branched morphology across the mouth-bar results in four shallow shoals, i.e. Chongming east shoal and Hengsha east shoal in the north delta, Jiuduansha shoal and Nanhui shoal in the south delta (Figure 1). The similar magnitude but opposite direction of net BSS over these shallow shoals under winter and summer wind waves results in an almost equal seaward and landward sediment mobility (green and black lines in Figure 11), from which we can infer no net long-term preferential direction of sediment flux for these shallow shoals; the effects offsetting each other. As the tidal wave is not a perfect standing wave, flood dominance at high tide and ebb dominance at low tide (Figure 12) tends to result in continued accumulation over the shallow shoals due to tidal asymmetry in both temporal and spatial dimensions. However, sedimentation does not persist over the resultant intermediate hypsometric profile, a factor which must be attributed to the disturbance by high frequency wind-waves. As a result, these four shallow shoals have a slightly different intertidal profile shape, reflecting the different exposures to prevailing southeast-northwesterly wind waves. Hengsha east shoal and Nanhui east shoal, to the south of the delta, have a more concave profile, and Chongming east shoal and Jiuduansha shoal, to the north, a more convex profile, despite the similar tidal range (Zhang et al., 2016a), sediment supply (Yang et al., 2006) and historic rate of sea level rise (Church et al., 2004). Therefore, the presence of wind waves is critical to the maintenance of inter-annual mouth-bar morphology, while the regime stability is dependent on the maintenance of seasonal shifts in the forcing conditions, i.e. seasonal variation of wind-waves. Any disturbances may result in possible regime shifts where the mouth-bar alternates between stable morphologies, i.e. a dynamic equilibrium process (Thorn and Welford, 1994; Zhou et al., 2017). Evidence from sedimentary cores (Wang et al., 2013) and sedimentation plates (Chen et al., 2000; Wei et al., 2007) suggests that the Yangtze Estuary may be close to such a dynamic equilibrium state. Morphological data (Dai et al., 2014; Wang et al., 2013; Luan et al., 2016) and hydrodynamic data (Wang et al., 2008, 2013) collected around the estuary also suggest that there is no significant long- or short-term sedimentation trend for at least the past 165 years. Generally, most estuaries around the world were formed with inundated river valleys during the rapid postglacial sea-level rise around 15,000-8,000 years B.P. (Wang et al., 2013). After the initial period of very rapid evolution (in geological time), a close to equilibrium state is regarded as a universal phenomenon for most ancient estuaries (Lanzoni and Seminara, 2002; Wang et al., 2013) . 


\subsection{Model limitations}

986

987

988

989

990

991

992

993

994

995

996

997

998

999

1000

1001

1002

1003

1004

1005

1006

1007

1008

1009

1010

1011

1012

1013

1014

1015

1016

1017

1018

1019

1020

1021

1022

1023

1024

1025

1026

The simplified hydrodynamic simulations, under the conditions of simplified river, tide and wave forcing, have allowed the potential drivers of morphological change to be explored and the resultant mouth-bar stability to be examined by considering the spatial and temporal variation in BSS. However, the real environment is complex and inevitably there are other factors that have not been considered.

Firstly, the most direct inaccuracy of BSS estimation arises from the use of uniform grain size, with no consideration of bed forms. A range of diameters of river discharged sediments are redistributed across the mouth-bar, reflecting the spatial variations in the hydrodynamics (Yang et al., 2000) and the bed forms also vary spatially (Liu et al., 2010). Soulsby and Clarke (2005) analytically demonstrated that BSS is positively correlated with sediment grain size and the presence of bed forms and that these vary in space and time. However, data is not available to support such an elaborate model containing these varying properties. Nevertheless, the primary interest of this study is the potential sediment mobility, where the focus is on the accumulated stress force over flood and ebb processes. Even at low force, some fraction of the finest grains in the bed may still be mobilized, whereas when forces increase above threshold values a reasonable fraction of bed sediments will be moved, which prescribe a benchmark value for potential sediment mobility of spatial and temporal comparison over the mouth-bar area.

Secondly, large episodic spate events could also disturb the regime stability, as a large flood could reshape morphology immediately (Cooper, 2002; Xu et al., 2005). However, floods usually cause a localized impact (Xu et al., 2005), and post-flood morphology has been observed to be restored under prevailing hydrologic conditions (Cooper, 2002). Thus, floods may have a significant short-term and localized impact, but are unlikely to be a significant factor in the seasonal patterns of morphological evolution, as shown for the mouth-bar area of the Yangtze Estuary.

Thirdly, it is possible that the seasonal cycle of the mouth-bar stability, due to the seasonal weather patterns, could be disturbed and become more elusory as the patterns of wind speed and direction change with climatic oscillations (e.g. La Niña and El Niño in the West Pacific). This may result in either accretion on shallow shoals under more summer wind dominance, or erosion on shallow shoals under more winter wind dominance. In addition, other biological and chemical processes like flocculation, vegetation and bio-stabilization may also contribute to the morphological response, and for a more thorough understanding, all the above mentioned natural factors should be considered.

Finally, there is growing evidence that anthropogenic interventions have outstripped natural forcing as the dominant factor in estuary evolution (Wei et al., 2016; Luan et al., 2016; Jeuken and Z., 2010). Reclamation, dredging, construction and regional shoal separation/mergence were relentless in the last century and their impacts on estuarine bathymetry warrant further examination.

\section{Summary and conclusions}

This study has used well-established numerical modeling tools to examine the interactions of river flow, tides and wind-waves and their respective contribution to potential sediment mobility. This has enabled the underlying processes that drive seasonal and spatio-temporal variation at 
the mouth of the Yangtze Estuary to be identified. The model results reveal a seasonal phenomenon as a dominant pattern in the mouth-bar area and well-defined spatial variability from shallow shoals to deep channels. From this we conclude:

(1) In a monsoon climate, river runoff exhibits a strong seasonal variation in magnitude and the wind-waves change direction with the seasons. The model results show that river-tide interaction is dominant within the river mouth, while outside the mouth at the bar area (above $-10 \mathrm{~m}$ ) the runoff effect is weak and the wave and tide influences are relatively strong, even during the larger discharge experienced during the wet season. Tidal currents tend to produce the largest BSS over the deeper part of the mouth-bar, whereas waves create the greatest BSS over the shallower shoals.

(2) The overall mouth-bar morphology of the Yangtze Estuary is tidally dominated. However, seasonal BSS analysis revealed that asymmetry in both temporal and spatial dimensions, due to wave-current interaction, induced variations in sediment motion over the shallow shoals. Hence, from the perspective of potential sediment mobility, the shallow shoals of the mouth-bar are wave dominated. Tidal effects in the deep channels and the lower parts of the shallow shoals were found to be ebb-dominant, but over the upper part of the shallow shoals, flood dominance prevailed. Wave effects proved to be important to induce sediment mobility on shallow shoals, which changes between flood and ebb dominance seasonally, in response to the changing wind-wave climate.

(3) BSS and its principal forcing processes varied spatially and temporally in the mouth-bar of Yangtze Estuary. Temporal tidal asymmetry maintains and deepens the channels, while the spatial tidal asymmetry reinforces the process of gradual growing of the shallow shoals. Wind-waves and river-tide currents combined to produce sediment mobility on shallow shoals throughout the entire year, the nature of which varies from winter to summer due to the seasonal monsoonal climate.

(4) Seasonal variation and the influence of wind-waves on tidal asymmetry, combined with river discharge has an important influence on the balance of mouth-bar morphology. When seaward BSS asymmetry exceeds the effect of diffusion onto the shallow shoals, sediment transport will be in a seaward direction and this occurs during the winter months. This then reverses to a landward direction under the influence of southeasterly summer wind-wave and is reinforced by the diffusion effect. As a result, the sedimentation on the shallow shoals has a seasonal characteristic of "summer storing and winter erosion".

(5) The long-term development of the Yangtze Estuary mouth-bar is most likely one of dynamic equilibrium, and has been shown to respond, often quite dramatically, to changes in natural and anthropic forcing (Dai et al., 2014; Dai et al., 2013; Wang et al., 2013). This study expands on this knowledge by presenting short to medium-scale results, which illustrate the importance of tides and seasonal wind-wave effects in balancing the movement of sediment on and around the mouth-bar. An understanding of how the mouth-bar develops an equilibrium over a range of temporal scales is important for the sustainable use and protection of the estuary.

Application of a similar modeling and analysis method to other estuaries will likely identify a similar combination of processes, however the relative importance of river, tide and wind-waves and their temporal and spatial feature on resultant sediment mobility maybe different according to local morphology, hydrology and atmospheric conditions. 


\begin{tabular}{|c|c|}
\hline Symbol & Description \\
\hline $\mathrm{C}$ & Wave phase speed (m/s) \\
\hline$C_{D}$ & The drag coefficient \\
\hline$C_{g}$ & Wave groups velocity $(\mathrm{m} / \mathrm{s})$ \\
\hline$D_{50}$ & Median grain size $(\mathrm{m})$ \\
\hline dxdy & Area of grid cell $\left(\mathrm{m}^{2}\right)$ \\
\hline$\dot{E}$ & The total energy head per unit width $\left(\mathrm{J} / \mathrm{m}^{2}\right)$ \\
\hline$E$ & The total energy input per unit cell over a complete tidal cycle (J) \\
\hline $\mathrm{F}$ & Wave spectrum \\
\hline$f$ & Wave frequency $(\mathrm{Hz})$ \\
\hline$f_{w}$ & The wave friction factor \\
\hline $\mathrm{g}$ & Gravity acceleration $\left(\mathrm{m} / \mathrm{s}^{2}\right), 9.8 \mathrm{~m} / \mathrm{s}^{2}$ \\
\hline $\mathrm{h}$ & Total water depth $(\mathrm{m})$ \\
\hline $\mathrm{H}_{s}$ & Significant wave height $(\mathrm{m})$ \\
\hline $\mathrm{i}, \mathrm{j}$ & Point to the two horizontal coordinates $\mathrm{x}$ and $\mathrm{y}$ \\
\hline $\mathrm{k}$ & Wave number \\
\hline $\mathrm{n}$ & Manning's coefficient $\left(\mathrm{sm}^{-1 / 3}\right)$ \\
\hline$\dot{\mathrm{P}}_{\text {cell }}$ & Energy dissipation per grid cell per second (W or $\mathrm{kg} \mathrm{m}^{2} / \mathrm{s}^{3}$ ) \\
\hline$\dot{\mathrm{P}}_{\mathrm{bss}}$ & Energy dissipation per grid cell per second due to BSS (W or $\mathrm{kg} \mathrm{m}^{2} / \mathrm{s}^{3}$ ) \\
\hline$\dot{\mathrm{P}}_{\mathrm{st}}$ & Energy dissipation per grid cell per second due to ST (W or $\mathrm{kg} \mathrm{m}^{2} / \mathrm{s}^{3}$ ) \\
\hline $\mathrm{P}_{\text {cell }}$ & Energy dissipation per grid cell over a tidal cycle $\left(\mathrm{J}\right.$ or $\left.\mathrm{kg} \mathrm{m}^{2} / \mathrm{s}^{2}\right)$ \\
\hline $\mathrm{P}_{\mathrm{bss}}$ & Energy dissipation per grid cell over a tidal cycle due to BSS $\left(\mathrm{J}\right.$ or $\left.\mathrm{kg} \mathrm{m}^{2} / \mathrm{s}^{2}\right)$ \\
\hline $\mathrm{P}_{\mathrm{st}}$ & Energy dissipation per grid cell over a tidal cycle due to ST (J or $\mathrm{kg} \mathrm{m}^{2} / \mathrm{s}^{2}$ ) \\
\hline $\mathrm{R}$ & Hydraulic radius $(\mathrm{m})$ \\
\hline $\mathrm{r}_{0}$ & Bed roughness \\
\hline $\mathrm{S}$ & Sediment transport $\left(\mathrm{m}^{3} / \mathrm{ms}\right)$ \\
\hline$S_{x}, S_{y}$ & Sediment transport in $\mathrm{x}$ and $\mathrm{y}$ direction $\left(\mathrm{m}^{3} / \mathrm{ms}\right)$ \\
\hline $\mathrm{S}_{\mathrm{h}}$ & Source terms of the mass continuity equation \\
\hline$S_{u}$ & Source terms of the momentum equation \\
\hline$S_{i j}$ & Components of the radiation stress tensor \\
\hline $\mathrm{T}$ & Period of tidal cycle (s), 12.5 hour for Yangtze Estuary \\
\hline $\mathrm{U}$ & Depth averaged flow velocity $(\mathrm{m} / \mathrm{s})$ \\
\hline $\mathrm{u}$ & Depth averaged velocity in $\mathrm{x}$ direction $(\mathrm{m} / \mathrm{s})$ \\
\hline $\mathrm{u}_{\mathrm{w}}$ & Near bed wave induced orbital velocity $(\mathrm{m} / \mathrm{s})$ \\
\hline $\mathrm{u}_{\mathrm{ce}}$ & Critical erosion velocity $(\mathrm{m} / \mathrm{s})$ \\
\hline $\mathrm{v}$ & Depth averaged velocity in y direction $(\mathrm{m} / \mathrm{s})$ \\
\hline$z_{0}$ & Zero datum of Huanghai1985 datum in this study (m) \\
\hline$z_{w s}$ & Mean water surface relative to a zero datum $\left(z_{0}\right)(\mathrm{m})$ \\
\hline$\alpha_{1}, \alpha_{2}$ & Constant parameters, 17.6 and $6.05 \times 10^{-7}$, respectively \\
\hline$\delta_{i j}$ & Kronecker symbol (=1 if i=j or 0 elsewhere) \\
\hline$\theta$ & Wave direction $\left(^{\circ}\right)$ \\
\hline
\end{tabular}




\begin{tabular}{|l|l|}
\hline$\varphi$ & Angle between wave direction and current direction $\left(^{\circ}\right)$ \\
\hline$\eta$ & Free surface variation $(\mathrm{m})$ \\
\hline$\rho_{\mathrm{w}}$ & Water density $\left(\mathrm{kg} / \mathrm{m}^{3}\right), 1027 \mathrm{~kg} / \mathrm{m}^{3}$ \\
\hline$\rho_{\mathrm{s}}$ & Sediment density $\left(\mathrm{kg} / \mathrm{m}^{3}\right), 2650 \mathrm{~kg} / \mathrm{m}^{3}$ \\
\hline$\kappa$ & Friction parameter $\kappa=\sqrt[6]{h} / \mathrm{n}\left(\mathrm{m}^{1 / 2} / \mathrm{s}\right)$ \\
\hline $\mathrm{K}_{\mathrm{e}}$ & The spatially varying coefficient depends on local sediment properties $(0.1 \sim 0.85)$ \\
\hline$\tau_{\mathrm{c}}$ & The current-along kinematic bed shear stress $(\mathrm{Pa})$ \\
\hline$\tau_{\mathrm{c} w}$ & The total bed shear stress $(\mathrm{Pa})$ \\
\hline$\tau_{\mathrm{w}}$ & The wave-along kinematic bed shear stress $(\mathrm{Pa})$ \\
\hline$\nu_{\mathrm{t}}$ & Momentum diffusion terms \\
\hline$\Delta$ & Relative density $\Delta=\left(\rho_{\mathrm{s}}-\rho_{\mathrm{w}}\right) / \rho_{\mathrm{w}}$ \\
\hline$\Lambda$ & Roughness height, $0.001 \mathrm{~m}$ \\
\hline
\end{tabular}

\section{Acknowledgements}

This research is supported by the National Natural Science Foundation of China (Project no.: 41701001) and NSFC-NOW-EPSRC Joint Research Projects (Project no.: 51761135024). Dr Hua Long Luan (Changjiang River Scientific Research Institute) is thanked for providing some of the parameterizations used in Critical Stress Thresholds (CST) calculation. The authors would like to express their appreciation to editor and two anonymous reviewers, who provided very helpful comments to improve the manuscript. In addition, we thank Dr Zeng Zhou from HoHai University who provided advice on Critical Stress Thresholds for cohesive beds.

\section{References:}

Bale, A.J., Morris, A.W. and Howland, R., 1985. Seasonal sediment movement in the tamar estuary. Oceanologica Acta, 8(1): 1-6.

Battjes, J. and Janssen, J., 1978. Energy Loss and Set-Up Due to Breaking of Random Waves. American Society of Civil Engineers, pp. 569-587. Bechtold, P. et al., 2008. Advances in simulating atmospheric variability with the ECMWF model: From synoptic to decadal time-scales. Quarterly Journal of the Royal Meteorological Society, 134(634): 1337-1351.

Benetazzo, A., Carniel, S., Sclavo, M. and Bergamasco, A., 2013. Wave-current interaction: Effect on the wave field in a semi-enclosed basin. Ocean Modelling, 70: 152-165. Berrisford, P. et al., 2011. The ERA-Interim archive Version 2.0. ECMWF, Shinfield Park, Reading, pp. 23.

Bolaños, R., Brown, J.M. and Souza, A.J., 2014. Wave-current interactions in a tide dominated estuary. Continental Shelf Research, 87: 109-123.

Bolla Pittaluga, M. et al., 2015. Where river and tide meet: The morphodynamic equilibrium of alluvial estuaries. Journal of Geophysical Research: Earth Surface, 120(1): 2014JF003233.

Cai, H., Savenije, H.H.G. and Toffolon, M., 2014. Linking the river to the estuary: Influence of river discharge on tidal damping. Hydrol.Earth Syst.Sci(18): 287-304.

1100 Carr, D., Gill, L.W. and McNabola, A., 2016. Development of a high resolution wave climate 
of Marine Energy, 16: 30-40.

Cavaleri, L. and Rizzoli, P.M., 1981. Wind wave prediction in shallow water: Theory and applications. Journal of Geophysical Research: Oceans, 86(C11): 10961-10973.

Chen, J., Zhu, H., Dong, Y. and Sun, J., 1985. Development of the Changjiang estuary and its submerged delta. Continental Shelf Research, 4(1-2): 47-56.

Chen, J.Y., Yun, C.X. and Xu, H.G., 1982. The model of development of the Changjiang estuary during the last 2000 years. In: Kennedy, V.S. (Ed.), Estuarine Comparisons. Academic Press, New York, pp. 655 - 666 .

Chen, Z., Song, B., Wang, Z. and Cai, Y., 2000. Late Quaternary evolution of the sub-aqueous Yangtze Delta, China: sedimentation, stratigraphy, palynology, and deformation. MARINE GEOLOGY, 162(2-4): 423-441.

Church, J.A., White, N.J., Coleman, R., Lambeck, K. and Mitrovica, J.X., 2004. Estimates of the Regional Distribution of Sea Level Rise over the 19502000 Period. Journal of Climate, 17(13): 2609-2625.

Cooper, J.A.G., 2002. The role of extreme floods in estuary-coastal behaviour: contrasts between riverand tide-dominated microtidal estuaries. Sedimentary Geology, 150(1-2): 123-137.

Dai, Z., Chu, A., Li, W., Li, J. and Wu, H., 2013. Has Suspended Sediment Concentration Near the Mouth Bar of the Yangtze (Changjiang) Estuary Been Declining in Recent Years? Journal of Coastal Research: 809-818.

Dai, Z., Fagherazzi, S., Mei, X., Chen, J. and Meng, Y., 2016. Linking the infilling of the North Branch in the Changjiang (Yangtze) estuary to anthropogenic activities from 1958 to 2013. Marine Geology, 379: $1-12$.

Dai, Z., Liu, J.T. and Wen, W., 2015. Morphological evolution of the South Passage in the Changjiang (Yangtze River) estuary, China. Quaternary International, 380 - 381: 314-326.

Dai, Z., Liu, J.T., Fu, G. and Xie, H., 2013. A thirteen-year record of bathymetric changes in the North Passage, Changjiang (Yangtze) estuary. Geomorphology, 187: 101-107.

Dai, Z., Liu, J.T., Wei, W. and Chen, J., 2014. Detection of the Three Gorges Dam influence on the Changjiang (Yangtze River) submerged delta., 4: 6600.

Dalyander, P.S., Butman, B., Sherwood, C.R., Signell, R.P. and Wilkin, J.L., 2013. Characterizing wave- and current- induced bottom shear stress: U.S. middle Atlantic continental shelf. Continental Shelf Research, 52: 73-86.

Dee, D.P. et al., 2011. The ERA-Interim reanalysis: configuration and performance of the data assimilation system. Quarterly Journal of the Royal Meteorological Society, 137(656): 553-597.

Dronkers, J., 1986. Tidal asymmetry and estuarine morphology. Netherlands Journal of Sea Research, 20(2): 117-131.

Du, J.L., Yang, S.L. and Feng, H., 2016. Recent human impacts on the morphological evolution of the Yangtze River delta foreland: A review and new perspectives. Estuarine Coastal \& Shelf Science, 181: 160-169.

Du, P., Ding, P. and Hu, K., 2010. Simulation of three-dimensional cohesive sediment transport in Hangzhou Bay, China. Acta Oceanologica Sinica, 29(2): 98-106.

EDF, R.D.S., 2011. TOMAWAC software for sea state modelling on unstructuredgrids over oceans and coastal seas. Release 6.1. France: EDF R\&D.

Engelund, F. and Hansen, E., 1967. A Monograph on Sediment Transport in Alluvial Streams, Teknisk Forlag, Copenhagen. 
Fan, Y., Ginis, I. and Hara, T., 2009. The Effect of Wind-Wave-Current Interaction on Air-Sea Momentum Fluxes and Ocean Response in Tropical Cyclones. Journal of Physical Oceanography, 39(4): 1019-1034.

Friedrichs, C.T. and Aubrey, D.G., 1988. Non-linear tidal distortion in shallow well-mixed estuaries: a synthesis. Estuarine, Coastal and Shelf Science, 27(5): 521-545.

Friedrichs, C.T. and Aubrey, D.G., 1996. Uniform Bottom Shear Stress and Equilibrium Hyposometry of Intertidal Flats. American Geophysical Union, pp. 405-429.

Frostick, L.E. and McCave, I.N., 1979. Seasonal shifts of sediment within an estuary mediated by algal growth. Estuarine and Coastal Marine Science, 9(5): 569-576.

Gong, Z., Zhang, C.K., Wan, L.M. and Zuo, J.C., 2012. Tidal Level Response to Sea-Level Rise in the Yangtze Estuary. China Ocean Engineering, 26(1): 109-122.

Guo, L. and He, Q., 2011. Freshwater flocculation of suspended sediments in the Yangtze River, China. Ocean Dynamics, 61(2): 371-386.

Guo, L., van der Wegen, M., Roelvink, J.A. and He, Q., 2014. The role of river flow and tidal asymmetry on 1-D estuarine morphodynamics. Journal of Geophysical Research: Earth Surface, 119(11): 2014JF003110.

Guo, Z., Yang, Z., Fan, D. and Pan, Y., 2003. Seasonal Sedimentary Effect on the Changjiang Estuary Mud Area (in chinese with english abstract). ACTA GEOGRAPHICA SINICA, 58(4): 591-597.

Haigh, I.D., Eliot, M. and Pattiaratchi, C., 2011. Global influences of the 18.61 year nodal cycle and 8.85 year cycle of lunar perigee on high tidal levels. Journal of Geophysical Research: Oceans, 116(C6): C06025.

Hashemi, M.R., Neill, S.P., Robins, P.E., Davies, A.G. and Lewis, M.J., 2015. Effect of waves on the tidal energy resource at a planned tidal stream array. Renewable Energy, 75: 626-639.

Hasselmann, K. et al., 1973. Measurements of wind-wave growth and swell decay during the Joint North Sea Wave Project (JONSWAP), TU Delft.

Hasselmann, S. and Hasselmann, K., 1985. Computations and Parameterizations of the Nonlinear Energy Transfer in a Gravity-Wave Spectrum. Part I: A New Method for Efficient Computations of the Exact Nonlinear Transfer Integral. Journal of Physical Oceanography, 15(11): 1369-1377.

Hunt, S., Bryan, K.R. and Mullarney, J.C., 2015. The influence of wind and waves on the existence of stable intertidal morphology in meso-tidal estuaries. Geomorphology, 228: 158-174.

Jeuken, M.C.J.L. and Z., B.W., 2010. Impact of dredging and dumping on the stability of ebb-flood channel systems. Coastal Engineering, 57(6): 553-566.

Jia, L., Wen, Y., Pan, S., Liu, J.T. and He, J., 2015. Wave-current interaction in a river and wave dominant estuary: A seasonal contrast. Applied Ocean Research, 52: 151-166.

Kirby, J.R. and Kirby, R., 2008. Medium timescale stability of tidal mudflats in Bridgwater Bay, Bristol Channel, UK: Influence of tides, waves and climate. Continental Shelf Research, 28(19): 2615-2629.

Kraeuter, J.N. and Wetzel, R.L., 1986. Surface sediment stabilization and suspended sediment cycles on an intertidal mudflat. In: Wolfe, D.A. (Ed.), Estuarine Variability. Academic Press, New York, pp. $203-223$.

Kuang, C. et al., 2017. River discharge contribution to sea-level rise in the Yangtze River Estuary, China. Continental Shelf Research, 134: 63-75.

Lanzoni, S. and Seminara, G., 2002. Long-term evolution and morphodynamic equilibrium of tidal channels. Journal of Geophysical Research: Oceans, 107(C1): 1-1-1-13. 
Li, M. et al., 2011. Morphodynamic characteristics of the dextral diversion of the Yangtze River mouth, China: tidal and the Coriolis Force controls. Earth Surface Processes and Landforms, 36(5): 641-650. Li, X., Gan, Y., Zhou, A. and Liu, Y., 2015. Relationship between water discharge and sulfate sources of the Yangtze River inferred from seasonal variations of sulfur and oxygen isotopic compositions. Journal of Geochemical Exploration, 153: 30-39.

Liu, H., He, Q., Wang, Z., Weltje, G.J. and Zhang, J., 2010. Dynamics and spatial variability of near-bottom sediment exchange in the Yangtze Estuary, China. Estuarine Coastal and Shelf Science, 86(3SI): 322-330.

Lu, Y., Li, S., Zuo, L., Liu, H. and Roelvink, J.A., 2015. Advances in sediment transport under combined action of waves and currents. International Journal of Sediment Research, 30(4): 351-360.

Luan, H.L., Ding, P.X., Wang, Z.B. and Ge, J.Z., 2017. Process-based morphodynamic modeling of the Yangtze Estuary at a decadal timescale: Controls on estuarine evolution and future trends. Geomorphology, 290: 347-364.

Luan, H.L., Ding, P.X., Wang, Z.B., Ge, J.Z. and Yang, S.L., 2016. Decadal morphological evolution of the Yangtze Estuary in response to river input changes and estuarine engineering projects. Geomorphology, 265: 12-23.

Malarkey, J. and Davies, A.G., 2012. A simple procedure for calculating the mean and maximum bed stress under wave and current conditions for rough turbulent flow based on Soulsby and Clarke's (2005) method. Computers \& Geosciences, 43: 101-107.

Milliman, J.D., Huang-ting, S., Zuo-sheng, Y. and H. Mead, R., 1985. Transport and deposition of river sediment in the Changjiang estuary and adjacent continental shelf. Continental Shelf Research, 4(1-2): $37-45$.

O Brien, D.J., Whitehouse, R.J.S. and Cramp, A., 2000. The cyclic development of a macrotidal mudflat on varying timescales. Continental Shelf Research, 20(12 - 13): 1593-1619.

Pensieri, S., Bozzano, R. and Schiano, M.E., 2010. Comparison between QuikSCAT and buoy wind data in the Ligurian Sea. Journal of Marine Systems, 81(4): 286-296.

Plagge, A.M., Vandemark, D.C. and Long, D.G., 2009. Coastal Validation of Ultra-high Resolution Wind Vector Retrieval From QuikSCAT in the Gulf of Maine. IEEE Geosci. Remote Sensing Lett., 6: 413-417.

Richards, K., 1982. Rivers, form and process in alluvial channels, Methuen \& Co Ltd, London.

Rodríguez-Iturbe, I. et al., 1992. Energy dissipation, runoff production, and the three-dimensional structure of river basins. Water Resources Research, 28(4): 1095-1103.

Satheesan, K., Sarkar, A., Parekh, A., Kumar, M.R.R. and Kuroda, Y., 2007. Comparison of wind data from QuikSCAT and buoys in the Indian Ocean. International Journal of Remote Sensing, 28(10): 2375-2382.

Soulsby, R.L. and Clarke, S., 2005. Bed Shear-Stresses Under Combined Waves and Currents on Smooth and Rough Beds. Report TR 137. HR Wallingford, Wallingford, UK, 22pp. /http://www.estproc.net/EstProc_library.htmS.

Thorn, C.E. and Welford, M.R., 1994. The equilibrium concept in geomorphology. Annals of the Association of American Geographers, 84(4): 666-696.

van der Wegen, M., Wang, Z.B., Savenije, H.H.G. and Roelvink, J.A., 2008. Long-term morphodynamic evolution and energy dissipation in a coastal plain, tidal embayment. Journal of Geophysical Research: Earth Surface, 113(F3): F03001.

Vlaswinkel, B.M. and Cantelli, A., 2011. Geometric characteristics and evolution of a tidal channel 
network in experimental setting. Earth Surface Processes and Landforms, 36(6): 739-752.

Wang, Y., Dong, P., Oguchi, T., Chen, S. and Shen, H., 2013. Long-term (1842 - 2006) morphological change and equilibrium state of the Changjiang (Yangtze) Estuary, China. Continental Shelf Research, 56: 71-81.

Wang, Y., Ridd, P.V., Wu, H., Wu, J. and Shen, H., 2008. Long-term morphodynamic evolution and the equilibrium mechanism of a flood channel in the Yangtze Estuary (China). Geomorphology, 99(1 4): $130-138$.

Wang, Z. et al., 2007. Plume front and suspended sediment dispersal off the Yangtze (Changjiang) River mouth, China during non-flood season. Estuarine, Coastal and Shelf Science, 71(1 - 2): 60-67.

Wang, Z. et al., 2013. Early to mid-Holocene rapid sea-level rise and coastal response on the southern Yangtze delta plain, China. Journal of Quaternary Science, 28(7): 659-672.

Wei, T. et al., 2007. Sedimentation rates in relation to sedimentary processes of the Yangtze Estuary, China. Estuarine Coastal and Shelf Science, 71(1-2): 37-46.

Wei, W. et al., 2015. Variations in tidal flats of the Changiiang (Yangtze) estuary during 1950s - 2010s: Future crisis and policy implication. Ocean \& Coastal Management, 108: 89-96.

Wei, W., Mei, X., Dai, Z. and Tang, Z., 2016. Recent morphodynamic evolution of the largest uninhibited island in the Yangtze (Changjiang) estuary during 1998 - 2014: Influence of the anthropogenic interference. Continental Shelf Research, 124: 83-94.

Xu, K. et al., 2005. Simulated sediment flux during 1998 big-flood of the Yangtze (Changjiang) River, China. Journal of Hydrology, 313(3-4): 221-233.

$\mathrm{Xu}, \mathrm{K}$. and Milliman, J.D., 2009. Seasonal variations of sediment discharge from the Yangtze River before and after impoundment of the Three Gorges Dam. Geomorphology, 104(3-4): 276-283.

Yang, S.L., Ding, P.X. and Chen, S.L., 2001. Changes in progradation rate of the tidal flats at the mouth of the Changjiang (Yangtze) River, China. Geomorphology, 38(1-2): 167-180.

Yang, S.L., Eisma, D. and Ding, P.X., 2000. Sedimentary processes on an estuarine marsh island in the turbidity maximum zone of the Yangtze estuary. Geo-Marine Letters, 20(2000): 87-92.

Yang, Z. et al., 2006. Dam impacts on the Changjiang (Yangtze) River sediment discharge to the sea: The past 55 years and after the Three Gorges Dam. Water Resources Research, 42(4): W04407.

Yu, P., Johannessen, J.A., Kudryavtsev, V., Zhong, X. and Zhou, Y., 2016. Radar imaging of shallow water bathymetry: A case study in the Yangtze Estuary. Journal of Geophysical Research: Oceans, 121(12): 8821-8839.

Zhang, E.F., Savenije, H.H.G., Chen, S.L. and Mao, X.H., 2012. An analytical solution for tidal propagation in the Yangtze Estuary, China. Hydrology and Earth System Sciences, 9(16): 3327-3339.

Zhang, M., Townend, I., Zhou, Y. and Cai, H., 2016a. Seasonal variation of river and tide energy in the Yangtze estuary, China. Earth Surface Processes and Landforms, 41(1): 98-116.

Zhang, M., Townend, I.H., Cai, H. and Zhou, Y., 2016b. Seasonal variation of tidal prism and energy in the Changjiang River estuary:a numerical study. Chinese Journal of Oceanology and Limnology(01): 219-230.

Zhou, Z. et al., 2015. Modeling sorting dynamics of cohesive and non-cohesive sediments on intertidal flats under the effect of tides and wind waves. Continental Shelf Research, 104: 76-91.

Zhou, Z. et al., 2017. Is “Morphodynamic Equilibrium” an oxymoron? Earth-Science Reviews, 165 : 257-267.

Zhu, Q., van Prooijen, B.C., Wang, Z.B. and Yang, S.L., 2017. Bed-level changes on intertidal wetland in response to waves and tides: A case study from the Yangtze River Delta. Marine Geology, 385: 
$160-172$.

1279 Zhu, Q., van Prooijen, B.C., Wang, Z.B., Ma, Y.X. and Yang, S.L., 2016. Bed shear stress estimation 1280 on an open intertidal flat using in situ measurements. Estuarine, Coastal and Shelf Science, 182, Part A: 1281 190-201.

1282 Zhu, Q., Yang, S. and Ma, Y., 2014. Intra-tidal sedimentary processes associated with combined 1283 wave-current action on an exposed, erosional mudflat, southeastern Yangtze River Delta, China. Marine Geology, 347: 95-106.

1285

1286

1287

1288

1289

1290

1291

1292

1293

1294 